\title{
Prophylactic Subacute Administration of Zinc Increases CCL2, CCR2, FGF2, and IGF-1 Expression and Prevents the Long-Term Memory Loss in a Rat Model of Cerebral Hypoxia-Ischemia
}

\author{
Victor Manuel Blanco-Alvarez, ${ }^{1}$ Guadalupe Soto-Rodriguez, ${ }^{1}$ \\ Juan Antonio Gonzalez-Barrios, ${ }^{2}$ Daniel Martinez-Fong, ${ }^{3}$ Eduardo Brambila, ${ }^{1}$ \\ Maricela Torres-Soto, ${ }^{1}$ Ana Karina Aguilar-Peralta, ${ }^{1}$ Alejandro Gonzalez-Vazquez, ${ }^{1}$ \\ Constantino Tomás-Sanchez, ${ }_{1}^{1}$ I. Daniel Limón, ${ }^{1}$ Jose R. Eguibar, ${ }^{4}$ Araceli Ugarte, ${ }^{4}$ \\ Jeanett Hernandez-Castillo, ${ }^{1}$ and Bertha Alicia Leon-Chavez ${ }^{1}$ \\ ${ }^{1}$ Facultad de Ciencias Químicas, BUAP, 14 Sur y Avenida San Claudio, 72570 Puebla, PUE, Mexico \\ ${ }^{2}$ Laboratorio de Medicina Genómica, Hospital Regional $1^{\circ}$ de Octubre, ISSSTE, Avenida Instituto Politécnico Nacional No. 1669, \\ 07760 México, DF, Mexico \\ ${ }^{3}$ Departamento de Fisiología, Biofísica y Neurociencias, Centro de Investigación y de Estudios Avanzados del \\ Instituto Politécnico Nacional, Apartado Postal 14-740, 07000 México, DF, Mexico \\ ${ }^{4}$ Instituto de Fisiología, BUAP, 14 Sur 6301, 72570 Puebla, PUE, Mexico
}

Correspondence should be addressed to Bertha Alicia Leon-Chavez; alileonch@gmail.com

Received 6 February 2015; Revised 30 May 2015; Accepted 1 June 2015

Academic Editor: Preston E. Garraghty

Copyright (C) 2015 Victor Manuel Blanco-Alvarez et al. This is an open access article distributed under the Creative Commons Attribution License, which permits unrestricted use, distribution, and reproduction in any medium, provided the original work is properly cited.

\begin{abstract}
Prophylactic subacute administration of zinc decreases lipoperoxidation and cell death following a transient cerebral hypoxiaischemia, thus suggesting neuroprotective and preconditioning effects. Chemokines and growth factors are also involved in the neuroprotective effect in hypoxia-ischemia. We explored whether zinc prevents the cerebral cortex-hippocampus injury through regulation of CCL2, CCR2, FGF2, and IGF-1 expression following a $10 \mathrm{~min}$ of common carotid artery occlusion (CCAO). Male rats were grouped as follows: (1) $\mathrm{Zn} 96 \mathrm{~h}$, rats injected with $\mathrm{ZnCl}_{2}$ (one dose every $24 \mathrm{~h}$ during four days); (2) $\mathrm{Zn} 96 \mathrm{~h}+\mathrm{CCAO}$, rats treated with $\mathrm{ZnCl}_{2}$ before CCAO; (3) CCAO, rats with CCAO only; (4) Sham group, rats with mock CCAO; and (5) untreated rats. The cerebral cortex-hippocampus was dissected at different times before and after CCAO. CCL2/CCR2, FGF2, and IGF-1 expression was assessed by RT-PCR and ELISA. Learning in Morris Water Maze was achieved by daily training during 5 days. Long-term memory was evaluated on day 7 after learning. Subacute administration of zinc increased expression of CCL2, CCR2, FGF2, and IGF-1 in the early and late phases of postreperfusion and prevented the CCAO-induced memory loss in the rat. These results might be explained by the induction of neural plasticity because of the expression of CCL2 and growth factors.
\end{abstract}

\section{Introduction}

The protective role of zinc in cerebral ischemia has been clearly sustained [1-3]. Several studies have shown that the ischemic preconditioning and postconditioning decrease intracellular zinc accumulation in a gerbil model of oxygenglucose deprivation, thus causing ischemic tolerance $[4,5]$. Interestingly, an increase in zinc at sublethal levels has also an effect similar to that of the ischemic preconditioning [6], involving caspase- 3 activation, PARP- 1 cleavage, and HSP70 induction, all of which are crucial for subsequent neuroprotection against glutamate excitotoxicity [2] and zinc toxicity $[7,8]$. An administration of zinc, protoporphyrin, superoxide dismutase $\mathrm{Zn}-\mathrm{Cu}$ (SOD), or PEP-SOD1 triggers protective mechanisms in different animal models and patients with cerebrovascular disease [9-12]. Some of these mechanisms 
are induction of metallothioneins, increase in the antioxidant capacity, increase in the growth factors such as GH, IGF1, and IGFBP3 $[13,14]$, and a decrease in the iron-catalyzed lipid peroxidation $[1,15,16]$. In addition, zinc participates in neural plasticity, promoting glutamate release and neuronal excitability in the central nervous system [17-19]. All these mechanisms lead to a decrease in inflammation and cell death $[1,3,12,16]$. Specifically in case of inflammation, zinc decreases the level of cytokines [16], importantly CCL2 and CCL3 [20].

In the cerebral ischemia/reperfusion-induced injury, proinflammatory cytokines and chemokines are rapidly upregulated. For instance, increased serum level of chemokines such as CCL2 (monocyte chemoattractant protein1), CCL5, and CXCL1 have been detected in the earlier days after ischemia [21-23]. During hypoxia-ischemia, the expression of CCL2 is known to be stimulated by the hypoxiainducible factor-1 (HIF-1) in astrocytes [24] and neurons [25]. Current evidence points out that the increased level of CCL2, CCL5, and CXCL1 during ischemia plays a dual role and could be either harmful or beneficial. This work is focused on CCL2 because it is one of the main chemokines that plays a major role in promoting leukocyte infiltration into the brain parenchyma during ischemia-induced inflammatory response $[26,27]$ and neuroregeneration including angiogenesis, neurogenesis, and synaptic plasticity [28-34].

The harmful effect of CCL2 has been related to its overexpression in astrocytes, which causes delayed death of the pyramidal neurons after ischemia [35]. The postulated mechanism is that the CCL2 favors the infiltration of macrophages and several leukocyte subtypes to the brain $[27,36,37]$ that produce neuroinflammation by increasing the permeability of brain endothelial blood-brain barrier [27, 38]. In support of the harmful effect, experiments in CCR2 (-/-) mice have concluded that the absence of the CCL2 receptor (CCR2) prevents the cerebral injury following ischemia/reperfusion [39].

The beneficial effect of CCL2 also is sustained by several experimental evidences. Hypoxic preconditioning induced CCL2 upregulation has been shown to participate in the ischemic tolerance [40, 41]. Similarly, CCR2 upregulation induced by either ischemic preconditioning or ischemic postconditioning also markedly prevents ischemia/reperfusioninduced cerebral injury as measured in terms of infarct size, loss of memory, and motor coordination [41]. The CCL2/CCR2 interaction also stimulates the chemotaxis of neural stem cells (NSCs) to the ischemic zone in the brain from the neurogenic niches as a compensatory mechanism to repair damaged brain after stroke [31]. A neurogenic role has also been attributed to insulin-like growth factor-1 (IGF-1) and CXCL12/SDF-1, which exert a considerable regulation on proliferation, migration, and survival of NSCs [42]. Cerebral mRNA expression of IGF1, FGF2, TGF, EGF, and PDGF-A has been observed in ischemic preconditioning $[43,44]$. Furthermore, administration of IGF-1 and FGF2 has been effective in preventing the ischemic stroke possibly promoting neuronal plasticity [45-50]. For instance, chronically elevated levels of CCL2 in the hippocampus produce hippocampal synaptic plasticity that block the depressing effects of ethanol [34].
In the current work, we hypothesized that the subacute administration of zinc ( $2.5 \mathrm{mg} / \mathrm{kg} \mathrm{ZnCl} 2$ every $24 \mathrm{~h}$ for 4 days) will exert an ischemic-like preconditioning and produce an increase in the expression of CCL2, CCR2, IGF-1, and FGF2 after a transient common carotid artery occlusion (CCAO) for $10 \mathrm{~min}$. Because estrogen and testosterone have been shown to be neuroprotective against ischemic insult $[51,52]$ and estrogen increases zinc levels in the brain [53], we used male rats to test our hypothesis. To the best of our knowledge, testosterone has not been related to increased levels of zinc in the brain. The beneficial effect of the subacute zinc administration will be reflected by the prevention of long-term memory loss that is induced by CCAO. RT-PCR and ELISA were used to illustrate the expression of CCL2, CCR2, IGF-1, and FGF2 in the cerebral cortex-hippocampus. CCR2 was also evaluated by immunofluorescence in slices of those regions. The Morris Water Maze was used to assess whether the subacute administration of zinc prevents the CCAO-induced loss of spatial reference memory. Our results suggest that the subacute administration of zinc has a protective effect in an animal model of cerebral-vascular disease.

\section{Materials and Methods}

2.1. Experimental Animals. Male Wistar rats between $190 \mathrm{~g}$ and $240 \mathrm{~g}$ ( 2 to 2.5 months old) were obtained from the vivarium of the CINVESTAV. Animals were maintained in adequate rooms with controlled conditions for temperature $(22 \pm$ $3^{\circ} \mathrm{C}$ ) and a light-dark cycle (12 h-12 h; light onset at 0700). Food and water were provided ad libitum. All procedures were in accordance with the Mexican current legislation, the NOM-062-ZOO-1999 (SAGARPA), based on the Guide for the Care and Use of Laboratory Animals, NRC. The Institutional Animal Care and Use Committee approved the experimental procedures with the protocol number 09-102. All efforts were made to minimize animal suffering.

2.2. Zinc Administration. Rats were grouped according to different treatments: (1) Zn96h, control rats treated with a subacute administration of zinc $\left(\mathrm{ZnCl}_{2} ; 2.5 \mathrm{mg} / \mathrm{kg}\right.$ every $24 \mathrm{~h}$ for 4 days). Brains were obtained at $24,48,72$, and $96 \mathrm{~h}$ during zinc administration, and at 4, 8, 12, 24, 36, 96, and $168 \mathrm{~h}$ after administration. (2) $\mathrm{Zn} 96 \mathrm{~h}+\mathrm{CCAO}$, rats were treated with a subacute administration of zinc and subjected to transient ischemia through a common carotid artery occlusion (CCAO) for $10 \mathrm{~min} 24 \mathrm{~h}$ after the last administration of zinc. (3) CCAO, rats with CCAO only. (4) Sham group, rats with mock CCAO. (5) Control, rats without any treatment. Brains were obtained at different hours $(4,8,12,24,36,96$, and $168 \mathrm{~h}$ after reperfusion) from animals of groups 2 to 4 . Brains obtained from control rats were considered as time $-96 \mathrm{~h}$.

2.3. Enzyme-Linked Immunosorbent Assay (ELISA). CCL2, CCR2, FGF2, and IGF-1 levels were measured by ELISA in homogenates of temporoparietal cortex-hippocampus $(n=5$ for each group), as described previously [54]. Protein content was determined using the method by Sedmak and Grossberg [55]. Aliquots containing $5 \mu \mathrm{g}$ of total protein were placed into wells of ELISA plates. Subsequently, $100 \mu \mathrm{L}$ of $0.1 \mathrm{M}$ 
TABLE 1: List of primers to amplify chemokine and growth factors.

\begin{tabular}{|c|c|c|c|c|}
\hline Sequence accession in NCBI & & Sequence & Position & Amplicon \\
\hline \multirow{2}{*}{ NM_019305.2 } & FGF2-f & GGAGTTGTGTCCATCAAGG & $736-754$ & \multirow{2}{*}{260} \\
\hline & FGF2-r & CCAATGTCTGCTAAGAGCTG & $996-977$ & \\
\hline \multirow{2}{*}{ NM_001082477.2 } & IGF1-f & TCGTCTTCACATCTCTTCTACC & $64-85$ & \multirow{2}{*}{381} \\
\hline & IGF1-r & GTGTACTTCCTTTCСTTCTCCT & $445-424$ & \\
\hline \multirow{2}{*}{ NM_031530.1 } & CCL2-f & GGAGAACTACAAGAGAATCACC & $218-239$ & \multirow{2}{*}{323} \\
\hline & CCL2-r & GCATCACATTCCAAATCACAC & $541-521$ & \\
\hline \multirow{2}{*}{ NM_021866.1 } & CCR2-f & CAGGGCTTTATCACATTGGG & $388-407$ & \multirow{2}{*}{311} \\
\hline & CCR2-r & AGATGACCATGACAAGTAGCG & $699-679$ & \\
\hline \multirow{2}{*}{ AF_10686 } & GA3PDH-f & AAAACAGTCCATGCCATCAC & $360-380$ & \multirow{2}{*}{420} \\
\hline & GA3PDH-r & TCCACCACCCTGTTGCTGTA & $780-759$ & \\
\hline
\end{tabular}

The primers were designed using Perl Primer V.1.1.19-1 (graphical design of primer for PCR) and their identity was analyzed using BLAST of the NCBI.

carbonate buffer was added into each well and the plates were incubated at $4^{\circ} \mathrm{C}$ for $18 \mathrm{~h}$. To block nonspecific binding sites, $200 \mu \mathrm{L}$ of $0.5 \%$ bovine serum albumin (IgG free) was added to each well at room temperature (RT). After $30 \mathrm{~min}$ of incubation, the wells were washed thrice with phosphate buffered saline- (PBS-) Tween 20 (0.1\%). Rabbit monoclonal antibodies to CCL2 (1:500 dilution; Cat. \# ab7202), CCR2 (1:500 dilution; Cat. \# ab21667), and FGF2 (1:500 dilution; Cat. \# ab106245) and mouse monoclonal antibody to IGF-1 (1:500 dilution; Cat. \# ab36532) were added into each well and incubated for $2 \mathrm{~h}$ at RT. All the antibodies were purchased from Abcam (Cambridge, MA, USA). After three washes with PBS, a horseradish-peroxidase conjugated goat antirabbit or mouse IgG (1:1000 dilution; Dako North America Inc; Carpinteria, CA, USA) was added into the wells and incubated for $2 \mathrm{~h}$ at RT. The antibody-antigen complex was revealed by adding $100 \mu \mathrm{L}$ of $2,2^{\prime}$-azino-bis(3-ethylbenzthiazoline-6-sulphonic acid) (ABTS) containing $0.3 \% \mathrm{H}_{2} \mathrm{O}_{2}$ into each well. After $15 \mathrm{~min}$, optical density (OD) was determined using a Benchmark multiplate reader at $415 \mathrm{~nm}$ (BioRad, Hercules, CA, USA) as described elsewhere [54]. All samples were made under the same experimental conditions and time.

2.4. Immunolabeling of CCR2. CCR2 was detected by indirect immunofluorescence techniques in coronal brain slices of Wistar rats ( $n=3$ in each group). Rats were deeply anesthetized with chloral hydrate and were perfused through the ascending aorta with $100 \mathrm{~mL}$ of PBS followed by $150 \mathrm{~mL}$ of $4 \%$ paraformaldehyde in PBS. Brains were then removed and maintained in a fixative at $4^{\circ} \mathrm{C}$ for $48 \mathrm{~h}$. Each brain was embedded in paraffin and then sectioned into $3 \mu \mathrm{m}$ slices on the sagittal plane using a Leica RM 2135 microtome (Leica Microsystems; Nussloch, Germany). Slices were individually collected on a glass slide. Tissue slices, previously deparaffinized, were rehydrated and incubated with $0.5 \%$ IgG-free bovine serum albumin in PBS-Tween 20 (0.1\%) for $20 \mathrm{~min}$ at room temperature. The primary antibody was the rabbit monoclonal anti-CCR2 (1:200 dilution; cat. \# ab32144, Abcam; Cambridge, MA, USA). The secondary antibody was a fluorescein (FITC) goat anti-rabbit IgG (1:60 dilution; Millipore; Temecula, CA, USA). The counterstaining was made using propidium iodide $(2 \mu \mathrm{g} / \mathrm{mL})$. Tissue slices were mounted on glass slides using Vectashield (Vector Laboratories; Burlington; Ontario, Canada). The fluorescence within the cells was analyzed with $5 \mathrm{x}$ and $40 \mathrm{x}$ objectives of a Leica DMIRE2 microscope using the filters K3 for FITC and TX2 for propidium iodide (Leica Microsystems; Wetzlar, Germany). Images were digitalized with a Leica DC300F camera (Leica Microsystems; Nussloch, Germany) and processed with a workstation Leica FW4000, version V1.2.1 (Leica Microsystems Vertrieb GmbH; Bensheim, Germany).

2.5. Reverse Transcriptase-Polymerase Chain Reaction. The RT-PCR technique was used to determine mRNA levels of the CCL2, CCR2, FGF2, IGF-1, and glyceraldehyde-3phosphate dehydrogenase (GA3PDH) as housekeeping gene in homogenates of temporoparietal cortex-hippocampus of controls and experimental groups ( $n=5$ for each group) as described elsewhere $[54,56]$. mRNA was extracted from $100 \mathrm{mg}$ of tissue (temporoparietal cortex and hippocampus) in $1 \mathrm{~mL}$ of TRizol reagent (Invitrogen, Life Technologies; Carlsbad, CA, USA), quantified by spectrophotometry at $260 \mathrm{~nm}$, and analyzed by using $1 \%$ agarose gel electrophoresis. Total RNA $(5 \mu \mathrm{g})$ was transcribed by using SuperScript III reverse transcriptase $(200 \mathrm{U})$ and $0.1 \mu \mathrm{g}$ of poli-T primer (Invitrogen; Carlsbad, CA; USA). Two $\mu \mathrm{L}$ of cDNA diluted $1: 4$ was amplified in a thermocycler (Gene Amp PCR System 9700; Applied Biosystems; Foster city, CA, USA) using $0.2 \mu \mathrm{M}$ of each sense and antisense primer (Table 1 ) and $2.5 \mathrm{U}$ of platinum Taq DNA polymerase in a final volume of $25 \mu \mathrm{L}$. After an initial denaturation at $94^{\circ} \mathrm{C}$ for $5 \mathrm{~min}$, amplification was made using 36 cycles as follows: denaturation, $94^{\circ} \mathrm{C}$ for 40 s (CCL2, CCR2, FGF2, IGF-1, and G3PDH); annealing, $57^{\circ} \mathrm{C}$ (CCL2, CCR2, FGF2, and IGF-1) and $55^{\circ} \mathrm{C}$ (GA3PDH) for $30 \mathrm{~s}$; and extension, $72^{\circ} \mathrm{C}$ for $20 \mathrm{~s}$ (CCR2, FGF2, IGF-1, and GA3PDH) and $10 \mathrm{~s}$ (CCL2). The PCR products were analyzed by using electrophoresis on $2 \%$ agarose gel prestained with ethidium bromide $(0.5 \mu \mathrm{g} / \mathrm{mL})$. Upon completion of electrophoresis, PCR products were photographed with a Kodak MI photodocumentation system (Mod. Gel Logic 200-E2000 V 5.0.1.30; Eastman Kodak Co; Rochester, NY, USA). Densitometric analysis was accomplished using the software Kodak MI (Eastman Kodak Co; Rochester, NY, 
USA). The densitometric values (arbitrary units) of the bands were normalized with respect to the densitometric values of GA3PDH band and with respect to the values of control without treatment. Expected size amplicons were cut from the gel and purified in the Zymo Spin columns (Zymo Research, CA 92614, USA). Posteriorly, all amplicons were sequenced by using capillary technology and detection system of fluorescence induced by laser in an automatic sequencer (Beckman Coulter, model CEQ 2000XL, SaintJulie, Quebec, Canada).

2.6. Spatial Reference Learning and Memory. The Morris Water Maze was used to measure the spatial reference memory. The measurements were conducted in a round tank, $150 \mathrm{~cm}$ in diameter and $80 \mathrm{~cm}$ deep, filled with water and divided into four imaginary quadrants. Water was maintained at a temperature of $23 \pm 2^{\circ} \mathrm{C}$ and dyed white with a titanium dioxide suspension to prevent the rats from locating the platform visually. Several distal visual cues were placed on both the walls of the Morris Water Maze and the room in which it had been installed. This evaluation consisted of five test days with four consecutive trials per day. During the trial, each animal was left in the tank facing the wall and allowed to swim freely to an escape platform $(40 \mathrm{~cm}$ in height and $15 \mathrm{~cm}$ in diameter), which was submerged by $2 \mathrm{~cm}$ under the water surface and conserved to the center of southeast quadrant of the tank. Rats were left in the tank on each of the four vertices of the imaginary quadrants. If the animals did not find the platform during a period of $60 \mathrm{~s}$ in the first trial of each test day, they were gently guided to it, allowed to remain on the platform for $30 \mathrm{~s}$, and removed from the tank for $30 \mathrm{~s}$. This procedure was used to ensure that the animals retained the visuospatial information of the maze online during the execution of the swimming task [57]. Long-term memory was evaluated in the absence of the platform on day 7 after learning. The latency to reach the platform and the number of times that rats pass by platform location were measured.

2.7. Statistical Analysis. The results for the difference between mRNA levels in various aged groups are expressed as mean \pm SEM. All assays were analyzed by using a one-way ANOVA test. Post hoc Dunnett's test was used to determine difference between the control group (without treatment) and treatment groups. The differences between the sham and control treated with zinc versus experimental groups (CCAO or Zn96h + CCAO) were determined using unpaired Student's $t$-test. The transcription change expressed in optical density (Fold change) was assessed by normalizing the sample test against GAD3PDH and untreated control. The normalized values for ELISAs are expressed as the sample test against untreated control. All statistical analyses were performed using the GraphPad Prism software (GraphPad Software Inc.; San Diego, CA, USA). $P$ values $<0.05$ were considered significant.

\section{Results}

Protein and mRNA levels of CCL2, CCR2, FGF2, and IGF1 were determined in the cerebral cortex-hippocampus to find out whether a subacute administration of zinc causes a preconditioning effect in CCAO model. Our results showed that 10 min CCAO did not modify the levels of CCL2 mRNA (Figure 1(a)) and protein (Figure 1(c)) after reperfusion when compared with the untreated control (time 0). A statistically significant difference was observed when mRNA values in the CCAO group were compared with the sham group at $12 \mathrm{~h}, 24 \mathrm{~h}, 36 \mathrm{~h}$, and $168 \mathrm{~h}$ (Figure $1(\mathrm{a})$ ) and for protein at $96 \mathrm{~h}$ (Figure 1(c)). The subacute administration of zinc produced upregulation of CCL2 mRNA by $169 \% \pm 17 \%$ at $48 \mathrm{~h}$ and $178 \% \pm 73 \%$ at $24 \mathrm{~h}$ before time 0 and by $151 \% \pm 4 \%$ at $96 \mathrm{~h}$ after time 0 (Figure 1(b)). After CCAO, no change in the level of CCL2 was observed in rats treated with zinc (Figure 1(b)). The CCL 2 protein levels increased by $146 \% \pm 27 \%$ at time 0 and by $64 \% \pm 12 \%$ at $12 \mathrm{~h}$ after reperfusion in rats treated with zinc (Figure 1(d)).

CCR2 mRNA levels in the sham group decreased overtime (Figure 2(a)). CCAO decreased CCR2 mRNA levels by $47 \pm 3 \%$ at $96 \mathrm{~h}$ after reperfusion with respect to those of time 0 (Figure 2(a)). The subacute administration of zinc increased CCR 2 mRNA levels by $291 \pm 92 \%$ at $-48 \mathrm{~h}$ and by $309 \pm$ $63 \%$ at $24 \mathrm{~h}$ in control rats (Figure $2(\mathrm{~b})$ ). CCAO produced upregulation of CCR 2 mRNA levels by $330 \pm 61 \%$ at $4 \mathrm{~h}$, by $207 \pm 56 \%$ at $8 \mathrm{~h}$, and by $30 \pm 6 \% 36 \mathrm{~h}$ after reperfusion only in rats treated with zinc (Figure 2(b)).

CCAO increased CCR2 protein levels by $66 \pm 4 \%$ at $8 \mathrm{~h}$ and by $75 \pm 43 \%$ at $168 \mathrm{~h}$ after reperfusion at time 0 and in comparison to the sham group (Figure 2(c)). The subacute administration of zinc increased CCR2 protein levels at time 0 by $146 \pm 27 \%$, by $46 \pm 4 \%$ at $8 h$, and by $32 \pm 0.2 \%$ at $36 \mathrm{~h}$ after reperfusion (Figure $2(\mathrm{~d})$ ).

The regional localization of CCR2 was explored using indirect immunofluorescence and propidium iodide counterstaining. CCR2 immunoreactivity (IR) was mainly localized in the granular zone of hippocampus (Figures 3 and 4) and in the pyramidal cells of layer III (data not shown) and V of cerebral cortex (Figures 3 and 4). The net intensity of CCR2 immunofluorescence was plotted (number of pixels per area) comparing each region with CCAO of Figures 3(a)3(o) against subacute administration of zinc after CCAO in Figures 4(a)-4(o), and these are showed in the graphs of Figure $4((\mathrm{p}),(\mathrm{q}),(\mathrm{r}),(\mathrm{s})$, and $(\mathrm{t}))$. In the CA1 region, CCAO (Figure 3(c)) caused a significant decrease in CCR2-IR by 79 \pm $15 \%$ at $168 \mathrm{~h}$ after reperfusion (Figure $4(\mathrm{p})$ ). In the cerebral cortex (Figure $3(\mathrm{k})$ ), the decrease was $46 \pm 2 \%$ at $24 \mathrm{~h}$ after reperfusion (Figure 4(s)) and in choroid plexus (Figure 3(o)); CCAO caused a decrease of CCR2-IR by $31 \pm 0.5 \%$ at $168 \mathrm{~h}$ after reperfusion (Figure $4(\mathrm{t})$ ). CCAO caused the loss of granular cell cytoarchitecture of CA1, CA3, and DG regions (Figures 3(a)-3(i)). Whereas the subacute administration of zinc caused a significant increase of CCR2 IR in the CA1 after $\mathrm{CCAO}$ at $24 \mathrm{~h}$ (Figure 4 (b)) by $202 \pm 5 \%$ and at $168 \mathrm{~h}$ after reperfusion (Figure 4 (c)) by $248 \pm 3 \%$ as shown in the graph (Figure $4(\mathrm{p}))$. The net intensity in CA3 after CCAO at $24 \mathrm{~h}$ (Figure $4(\mathrm{e})$ ) increased $44 \pm 2 \%$ and at $168 \mathrm{~h}$ after reperfusion (Figure $4(\mathrm{f})$ ) by $62 \pm 2 \%$ as shown in the graph (Figure $4(\mathrm{q})$ ). In the DG (Figures 4(h) and 4(i)), CCR2 IR increased by $53 \pm 3 \%$ at $24 \mathrm{~h}$ and by $75 \pm 2 \%$ at $168 \mathrm{~h}$ after reperfusion (Figure $4(\mathrm{r})$ ). In layer $\mathrm{V}$ of cerebral cortex (Figures $4(\mathrm{k})$ and $4(\mathrm{l})$ ), CCR 2 IR increased by $337 \pm 5 \%$ at $24 \mathrm{~h}$ and by $324 \pm 7 \%$ 

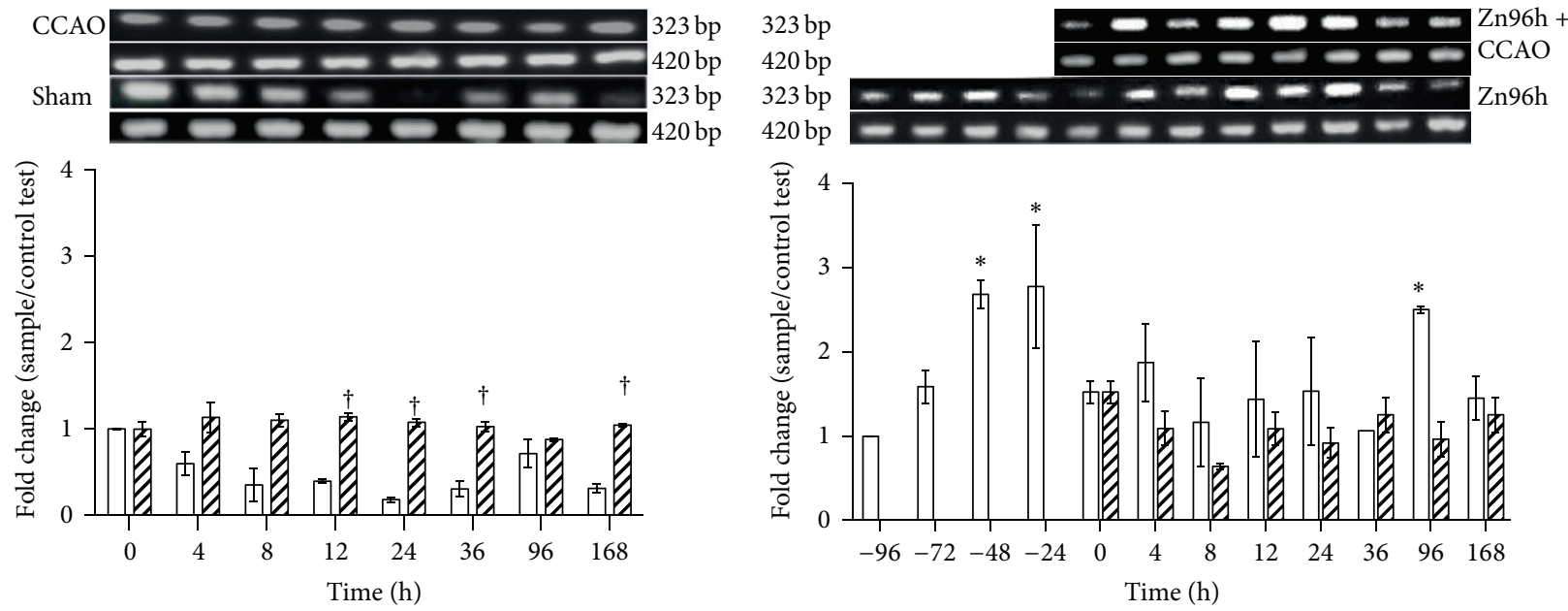

$\square$ Sham

ZII $\mathrm{Zn} 96 \mathrm{~h}+\mathrm{CCAO}$

(a)
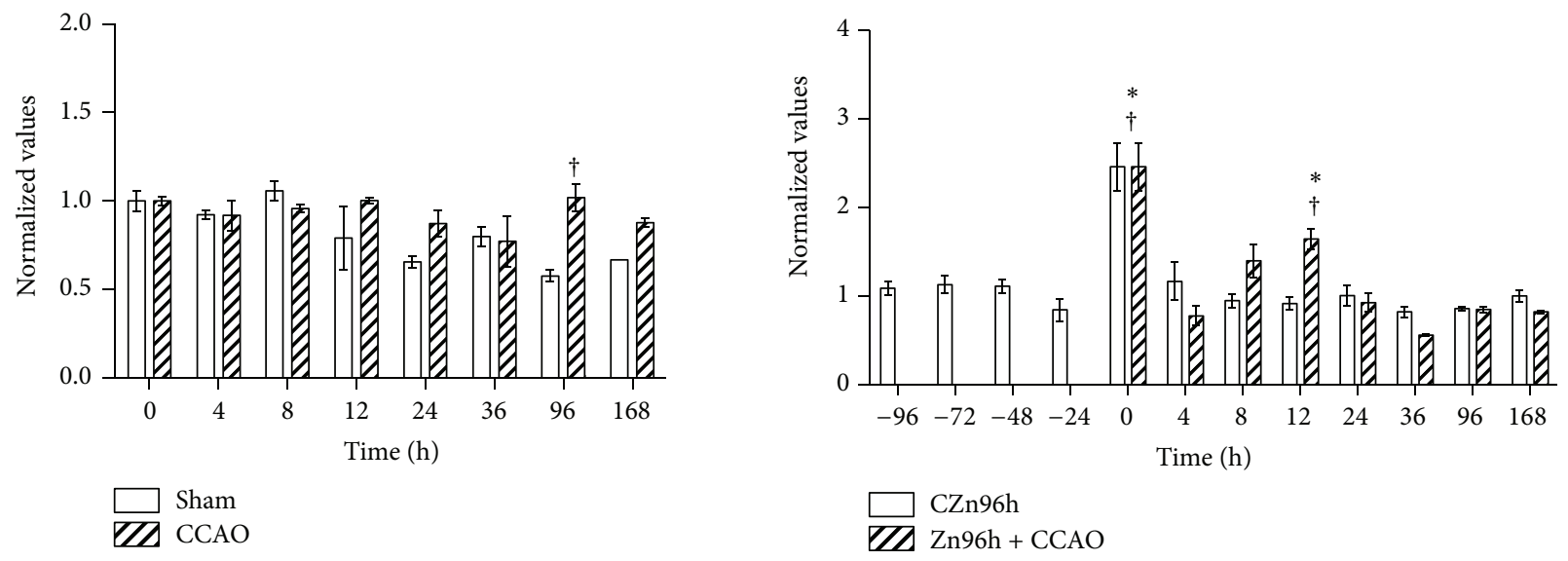

(c)

(d)

FIGURE 1: Effect of subacute administration of zinc on CCL2 expression in cerebral cortex-hippocampus of the rat. RT-PCR was used to determine mRNA levels of CCL2 (323 bp) and GA3PDH (420 bp). ((a) and (b)) Showing representative photographs of ethidium-bromidestained RT-PCR products fractionated on $2 \%$ agarose gel and the respective densitometry analysis. ((c) and (d)) Showing the CCL2 protein levels using ELISA. Each value represents the mean \pm SEM of 5 independent experiments made in triplicate. (1) Zn96h, rats injected with $\mathrm{ZnCl}_{2}$ (one dose every $24 \mathrm{~h}$ during 4 days). (2) $\mathrm{Zn} 96 \mathrm{~h}+\mathrm{CCAO}$, rats treated with zinc before 10 min of common carotid artery occlusion (CCAO). (3) CCAO, rats with CCAO only. (4) Sham group, rats with mock CCAO. (5) Untreated rats. *, significant when compared with the control group; ANOVA test and post hoc Dunnett's test. $\dagger$, significant when compared between groups; unpaired Student's $t$-test. $P<0.05$.

at $168 \mathrm{~h}$ after reperfusion (Figure $4(\mathrm{~s})$ ). In the choroid plexus (Figure $4(\mathrm{o})$ ), CCR2 IR increased by $88 \pm 2 \%$ at $168 \mathrm{~h}$ after reperfusion (Figure $4(\mathrm{t})$ ). In choroid plexus, the CCR2 IR increased at $168 \mathrm{~h}$ after reperfusion (Figure $4(\mathrm{o})$ ) by $88 \pm 2 \%$ as shown in the graph (Figure 4(t)).

RT-PCR and ELISA were used to identify whether the subacute administration of zinc modifies the expression of FGF2 (Figure 5) and IGF1 (Figure 6) after CCAO. An increase in FGF 2 mRNA levels by $40 \pm 9 \%$ at $12 \mathrm{~h}$ and by $37 \pm 6 \%$ at $96 \mathrm{~h}$ was detected after reperfusion (Figure 5(a)). The subacute administration of zinc caused a further increase in FGF2 mRNA by $214 \pm 55 \%$ at $4 \mathrm{~h}, 141 \pm 42 \%$ at $8 \mathrm{~h}, 149 \pm 35 \%$ at $24 \mathrm{~h}$, and $75 \pm 9 \%$ at $36 \mathrm{~h}$ after reperfusion (Figure 5(b)).
CCAO also increased FGF2 protein levels by $25 \pm 6 \%$ at $96 \mathrm{~h}$ after reperfusion when compared to the control (time 0 ; Figure 5(c)). The subacute administration of only zinc increased FGF2 protein levels by $33 \pm 13 \%$ at $4 \mathrm{~h}$ with respect to the last administration (Figure 5(d)), while CCAO caused two further increases, first by $30 \pm 3 \%$ in the early phase $(12 \mathrm{~h})$ and the second by $33 \pm 4 \%$ in the late phase ( $36 \mathrm{~h})$ after reperfusion in rats treated with zinc (Figure 5(d)).

CCAO decreased IGF-1 mRNA levels by $69 \pm 16 \%$ at $4 \mathrm{~h}$ and by $94 \pm 6 \%$ at $24 \mathrm{~h}$ after reperfusion when compared to the control at time 0 (Figure 6(a)). A significant decrease of $82 \pm 7 \%$ in IGF1 mRNA levels was observed at $24 \mathrm{~h}$ after mock surgery (Figure 6(a), white bars). The subacute 

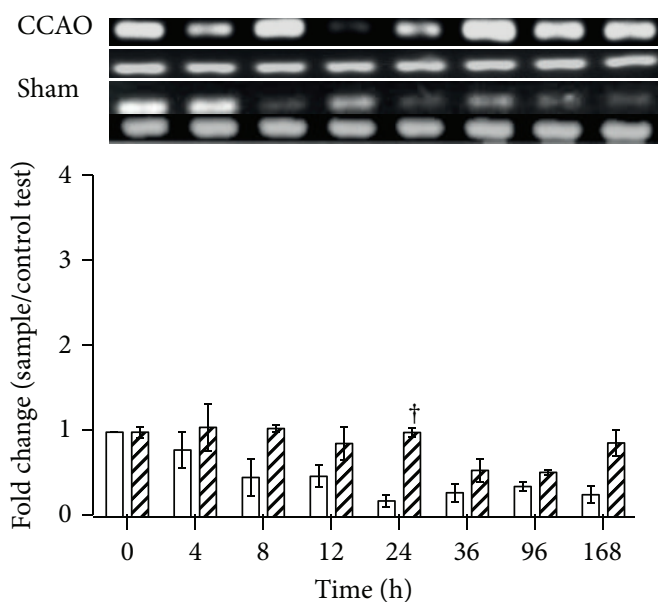

$\square$ Sham

(a)

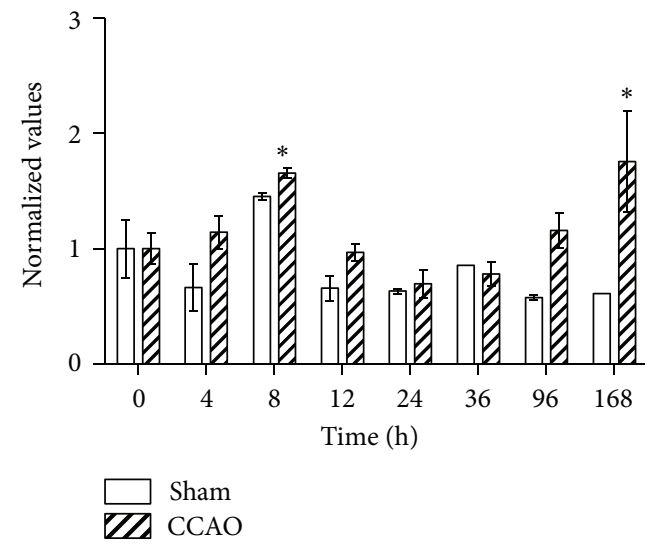

(c)
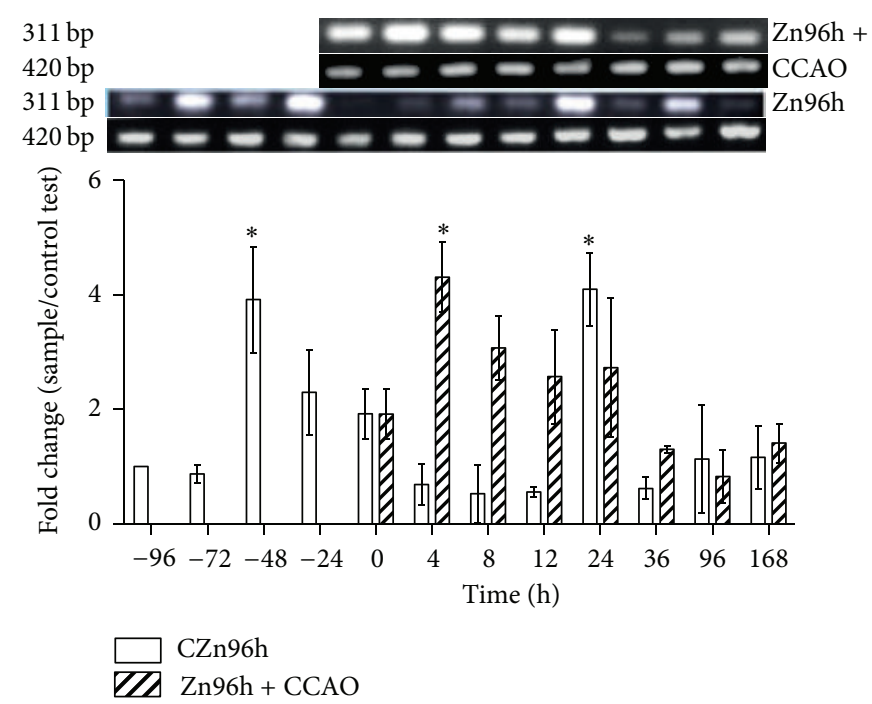

(b)

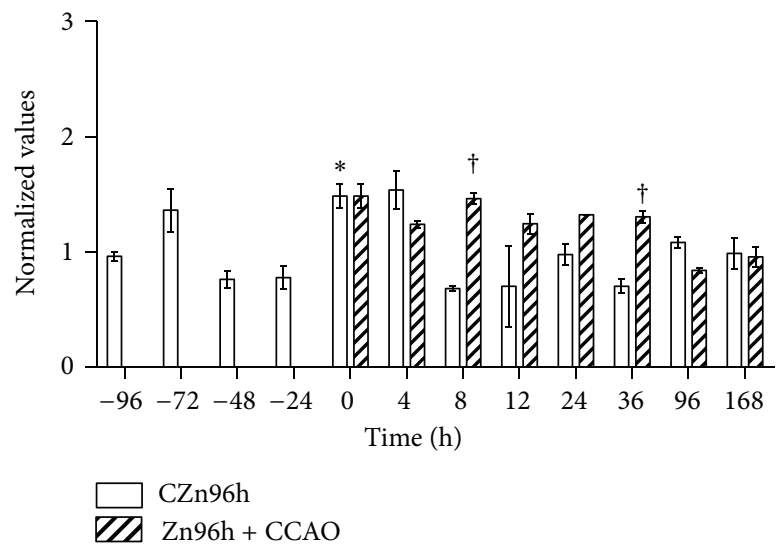

(d)

FIGURE 2: The subacute administration effect of zinc on levels of CCR2 expression after hypoxia-ischemia in rats. RT-PCR was used to determine mRNA levels of CCR2 (311 bp) and GA3PDH (420 bp). ((a) and (b)) Showing representative photographs of ethidium-bromidestained RT-PCR products fractionated on $2 \%$ agarose gel and the respective densitometry analysis. ((c) and (d)) Showing the CCR2 protein levels measured using ELISA. Each value represents the mean \pm SEM of 5 independent experiments in triplicate. (1) Zn96h, rats injected with $\mathrm{ZnCl}_{2}$ (one dose every $24 \mathrm{~h}$ during 4 days). (2) $\mathrm{Zn} 96 \mathrm{~h}+\mathrm{CCAO}$, rats treated with zinc before 10 min of common carotid artery occlusion (CCAO). (3) CCAO, rats with CCAO only. (4) Sham group, rats with mock CCAO. (5) Untreated rats. *, significant when compared with the control group; ANOVA test and post hoc Dunnett's test. $\uparrow$, significant when compared between groups; unpaired Student's $t$-test. $P<0.05$.

administration of only zinc increased IGF1 mRNA levels by $77 \% \pm 15 \%$ before time 0 (Figure $5(\mathrm{~b})$ ) from $-48 \mathrm{~h}$ until time 0 and these values were normalized to the basal values after time 0 . CCAO maintained the zinc-induced upregulation until $8 \mathrm{~h}$ after reperfusion in rats treated with zinc (Figure 6(b)).

CCAO increased IGF1 protein levels by $37 \pm 7 \%$ at $24 \mathrm{~h}$, $71 \pm 11 \%$ at $96 \mathrm{~h}$, and $42 \pm 7 \%$ at $168 \mathrm{~h}$ after reperfusion when compared with the control at time 0 (Figure 6(c)), whereas the subacute administration of zinc increased IGF-1 levels by $41 \pm 9 \%$ at $8 \mathrm{~h}$, with a maximum of $106 \pm 0.1 \%$ at $12 \mathrm{~h}$ in the early phase after CCAO, and by $164 \pm 3 \%$ at $96 \mathrm{~h}$ and $178 \pm 5 \%$ at the $168 \mathrm{~h}$ after reperfusion (Figure $6(\mathrm{~d})$ ).

To evaluate whether the subacute administration of zinc prevents the $\mathrm{CCAO}$-induced neuronal damage in the hippocampus, spatial reference learning, and memory was assessed using Morris Water Maze. CCAO increased the learning latency by $291 \pm 119 \%$ on day 5 with respect to the untreated group (Figure 7(a)). Interestingly, the subacute administration of zinc alone significantly decreased the learning latency (Figure 7(b)) compared to the untreated group (Figure 7(a)), suggesting that the learning was improved. Furthermore, the subacute administration of zinc prevented the CCAO-induced increase on day 5 (Figure 7(b)). CCAO also increased the latency by $43 \pm 6 \%$ on day 7 after the learning training, which was on day 12 after reperfusion (Figure $7(\mathrm{c})$ ). Remarkably, the subacute administration of zinc alone decreased the latency by $64.4 \pm 4.8 \%$ when compared with the untreated group and prevented the hypoxia-ischemiainduced increase on day 12 after reperfusion (Figure $7(\mathrm{c})$ ). 


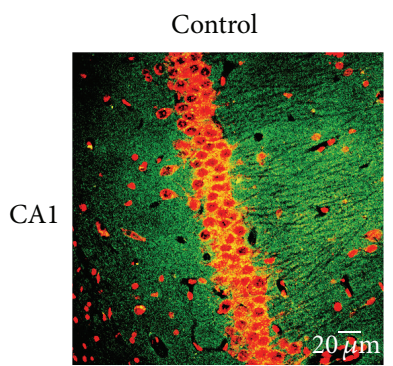

(a)

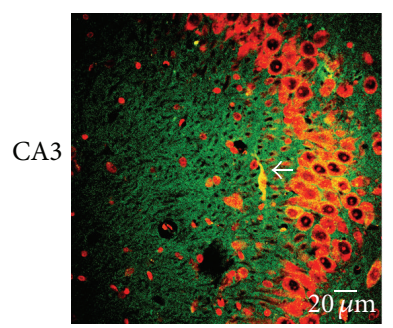

(d)

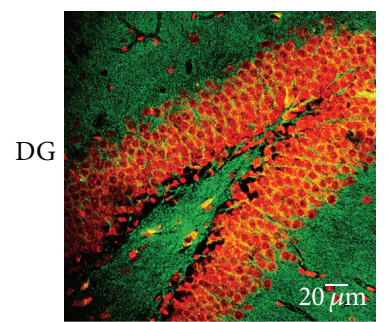

(g)

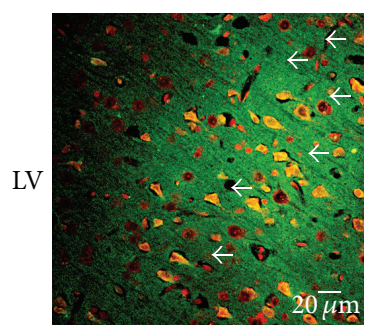

(j)

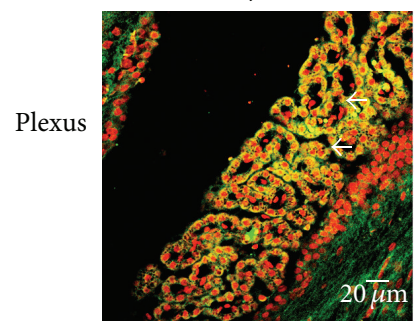

(m)

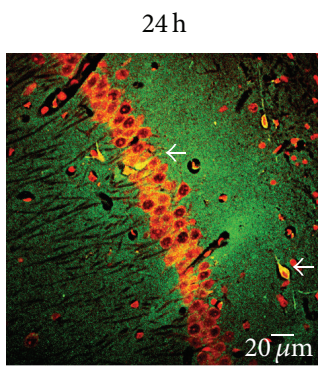

(b)

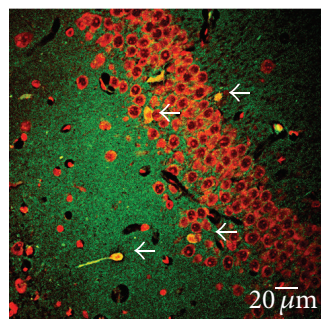

(e)

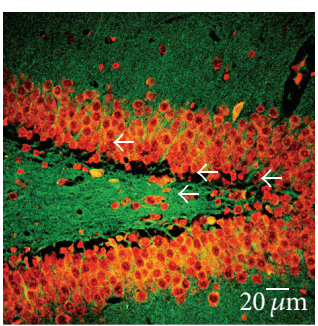

(h)

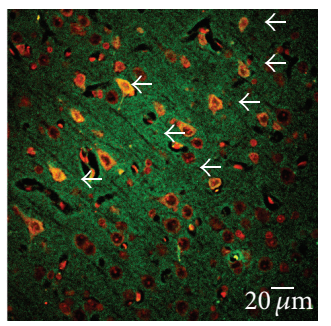

(k)

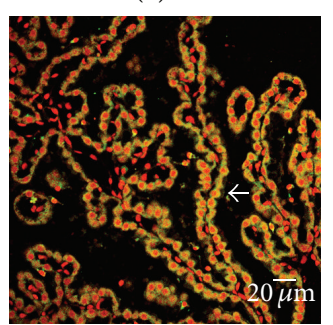

(n)

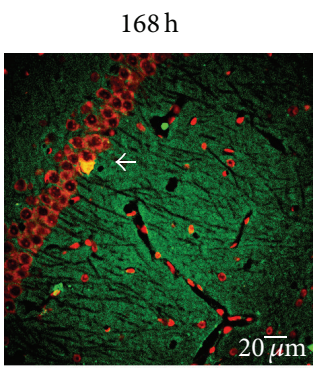

(c)

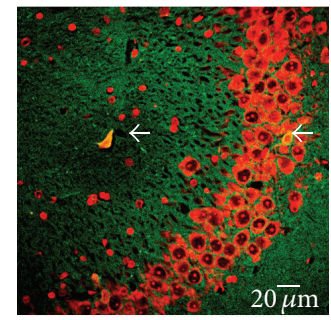

(f)

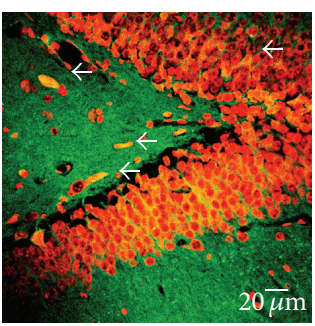

(i)

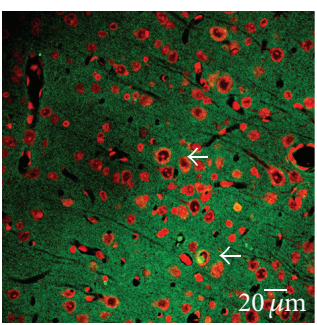

(1)

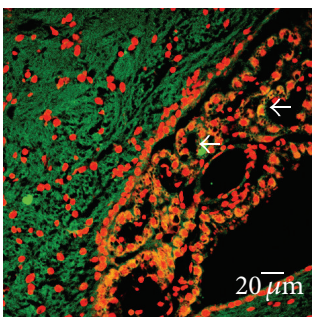

(o)

FIGURE 3: Effect of common carotid artery occlusion on the immunoreactivity against CCR2. Representative micrographs of CCR2 immunofluorescence ((a) to (o)) using a rabbit antibody against CCR2 and a goat antibody anti-rabbit IgG conjugated with fluorescein isothiocyanate (green color). The cerebral region was identified by propidium iodide (red color) counterstaining. CA, Cornu Ammonis, and DG, dentate gyrus, of the hippocampus. LV, layer V of the cerebral cortex. Plexus, choroid plexus. Values are the mean \pm SEM from 3 rats in each experimental condition. 


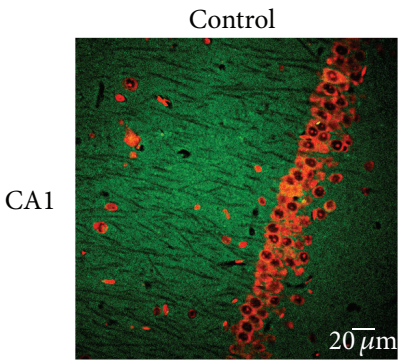

(a)

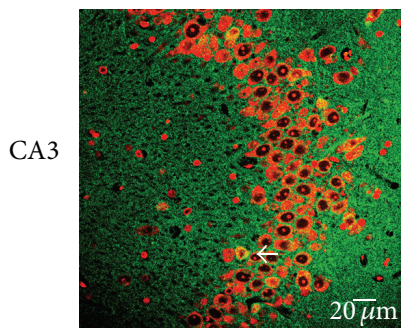

(d)

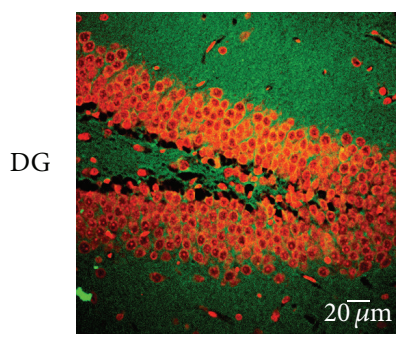

(g)

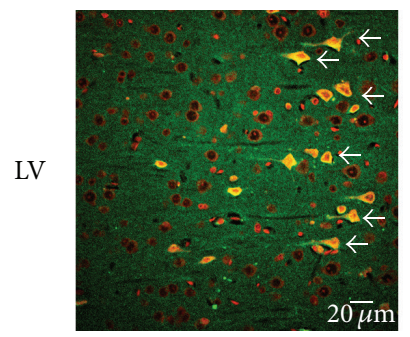

(j)

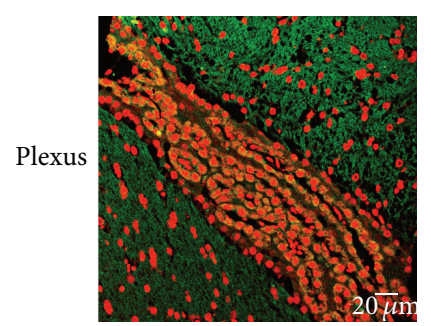

(m)

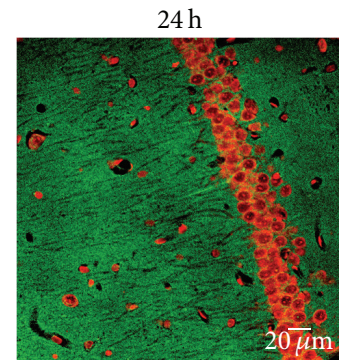

(b)

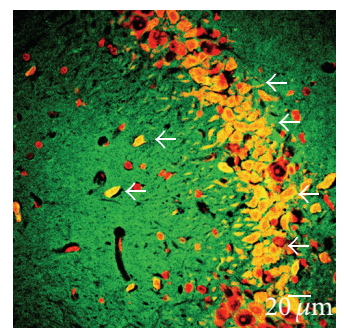

(e)

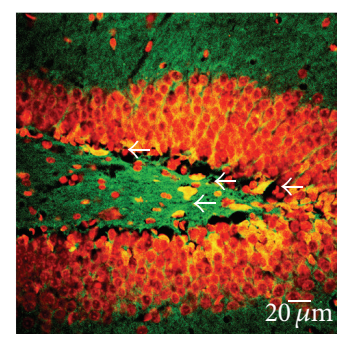

(h)

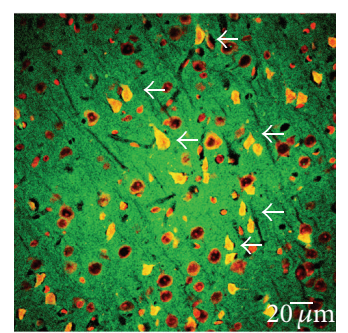

(k)

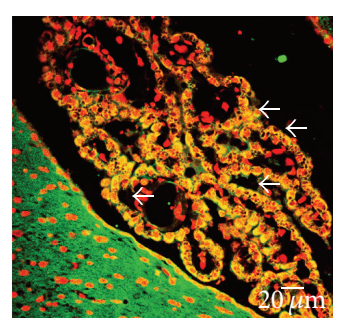

(n)

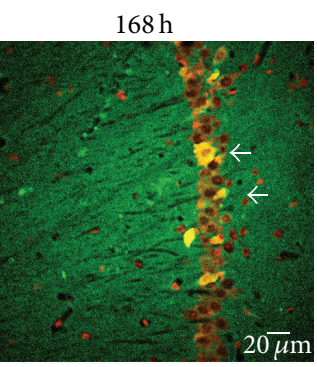

(c)

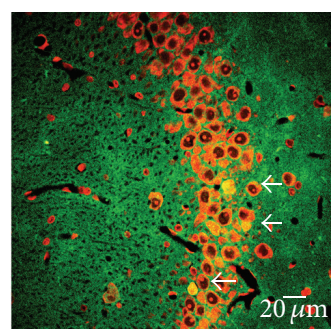

(f)

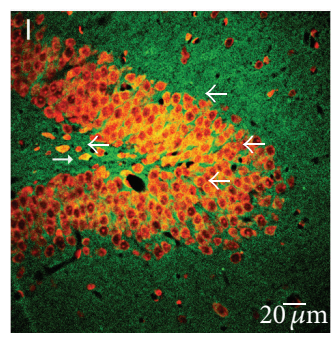

(i)

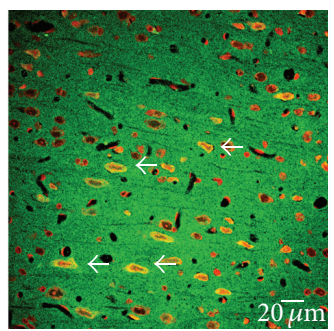

(1)

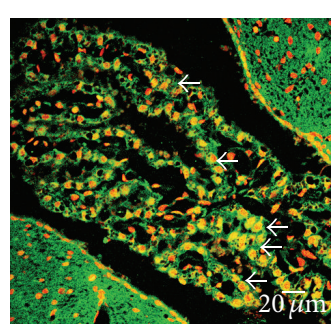

(o)

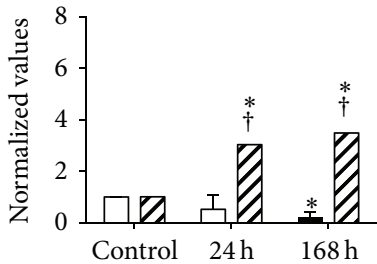

Time (days after-reperfusion)

(p)

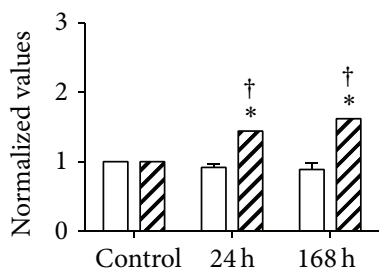

Time (days after-reperfusion)

(q)

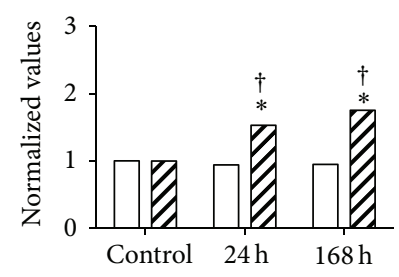

Time (days after-reperfusion)

(r)

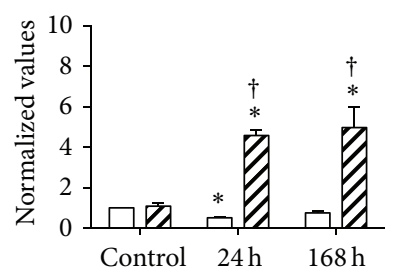

Time (days after-reperfusion)

(s)

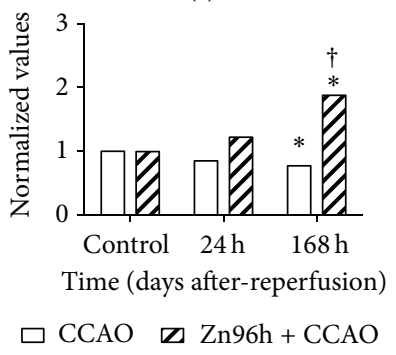

(t)

FIGURE 4: Effect of the subacute administration of zinc on CCR2 immunoreactivity after CCAO. Representative micrographs of CCR2 immunofluorescence ((a) to (o)) using a rabbit antibody against CCR2 and a goat antibody anti-rabbit IgG conjugated with fluorescein isothiocyanate (green color). The cerebral region was identified with propidium iodide (red color) counterstaining. Graphs ((p), (q), (r), (s), and $(\mathrm{t})$ ) show the normalized values of CCR2-IR with respect to control IR for CCAO (Figures 3(a) to 3(o)) and subacute administration of zinc ((a) to (o)). The IR was measured using ImageJ 1.45 of the National Institute of Health. CA, Cornu Ammonis, and DG, dentate gyrus, of the hippocampus. LV, layer V of the cerebral cortex. Plexus, choroid plexus. Values are expressed as the mean \pm SEM from 3 rats for each experimental condition. $*$, significant when compared with the control group; ANOVA test and post hoc Dunnett's test. $\dagger$, significant when compared between groups; unpaired Student's $t$-test. $P<0.05$. 

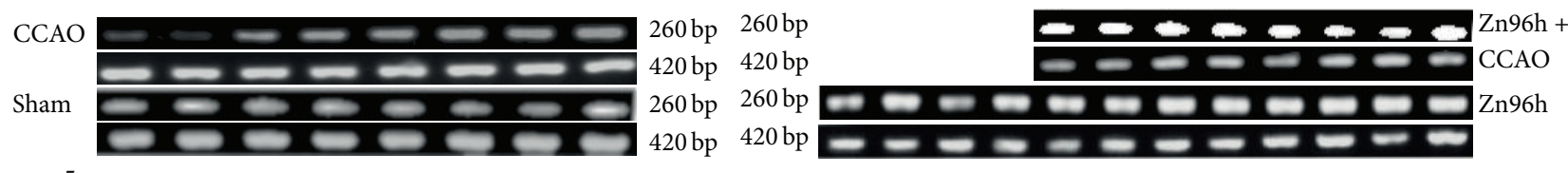

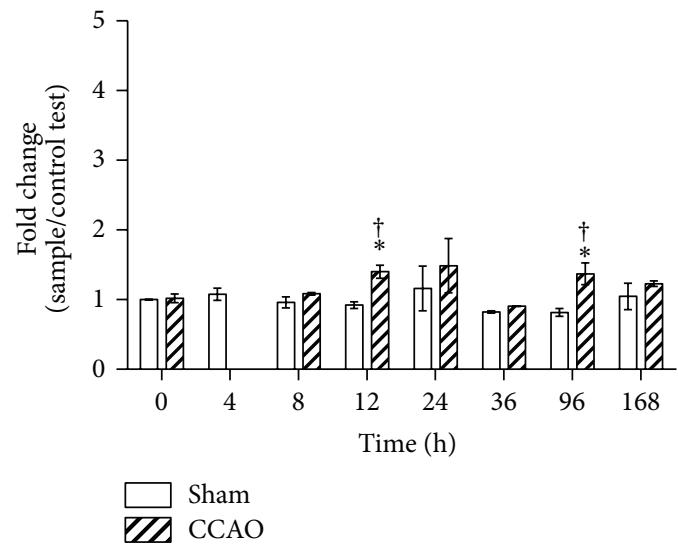

(a)

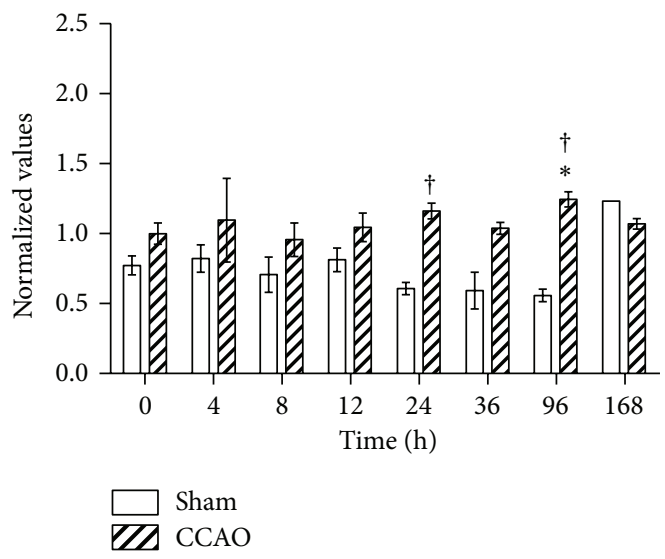

(c)
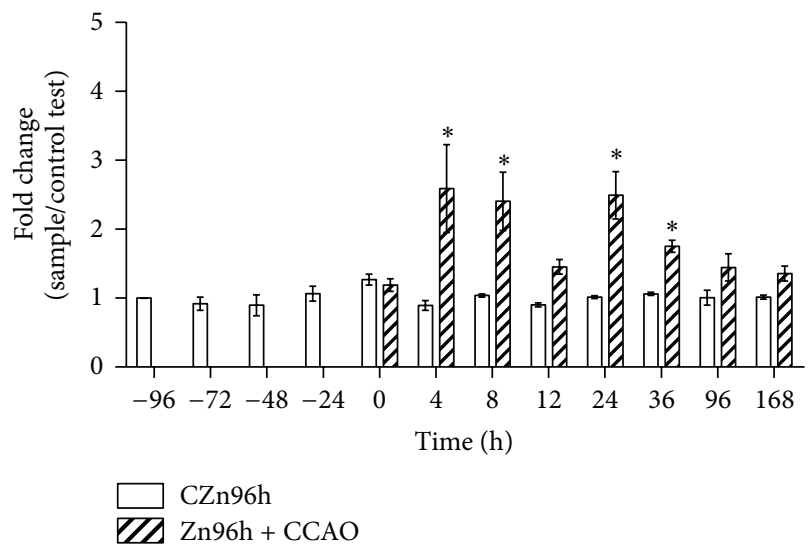

(b)

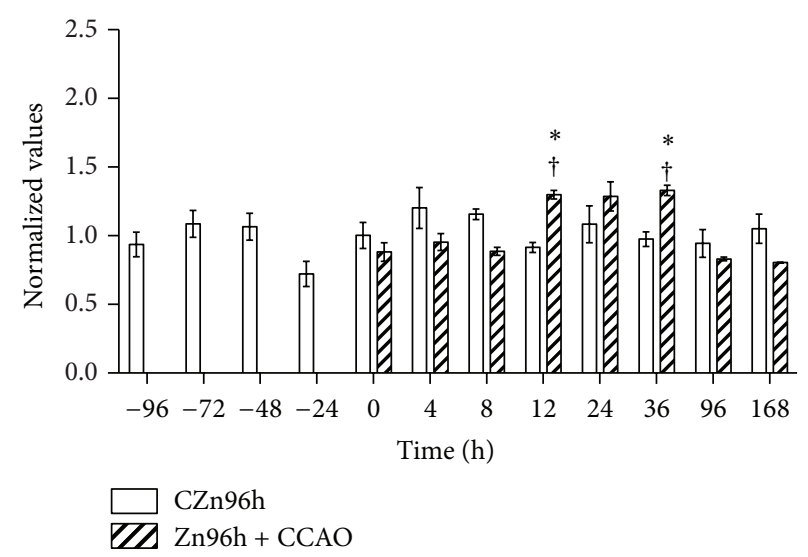

(d)

FIGURE 5: The subacute administration effect of zinc on FGF2 expression levels after hypoxia-ischemia in the rat. RT-PCR was used to determine mRNA levels of FGF2 (260 bp) and GA3PDH (420 bp). ((a) and (b)) Showing representative photographs of ethidium-bromidestained RT-PCR products fractionated on $2 \%$ agarose gel and the respective densitometry analysis. ((c) and (d)) Showing the FGF2 protein levels measured using ELISA. Each value represents the mean \pm SEM of 5 independent experiments made in triplicate. (1) Zn96h, rats injected with $\mathrm{ZnCl}_{2}$ (one dose every $24 \mathrm{~h}$ during 4 days). (2) $\mathrm{Zn} 96 \mathrm{~h}+\mathrm{CCAO}$, rats treated with zinc before 10 min common carotid artery occlusion (CCAO). (3) CCAO, rats with CCAO only. (4) Sham group, rats with mock CCAO. (5) Untreated rats. *, significant when compared with the control group; ANOVA test and post hoc Dunnett's test. $\dagger$, significant when compared between groups; unpaired Student's $t$-test. $P<0.05$.

In addition, the number of times at which rats pass by the platform location was decreased by $50 \%$ in the CCAO group as compared with the untreated control group. Such decrease was prevented by the prophylactic subacute administration of zinc (Figure $7(\mathrm{~d})$ ), thus suggesting retention of long-term memory.

\section{Discussion}

Our results show that the prophylactic subacute administration of zinc causes a neuroprotective effect in the hippocampus and cerebral cortex, by increasing the expression of neurotrophic factors CCL2, CCR2, FGF2, and IGF-1 in the early and late phases after transient hypoxia-ischemia process and preventing the loss of the long-term in spatial reference memory as evaluated in the Morris Water Maze. Supporting the neuroprotective effect, previous studies have demonstrated that zinc decreases the nitrosative stress, inflammatory cytokines, and cell death after hypoxia-ischemia process and atherosclerosis $[1,3,16]$.

The subacute administration of zinc induced CCL2 expression in the early phase after reperfusion. A mechanism that might mediate the upregulation of CCL2 is the activation of the zinc finger transcription factor ZXDC in astrocytes and microglial cells, known to be antigen-presenting cells in the central nervous system [58]. This suggestion is supported by the finding that the overexpression of zinc finger transcription factor ZXDC induces CCL2 gene expression in antigen 

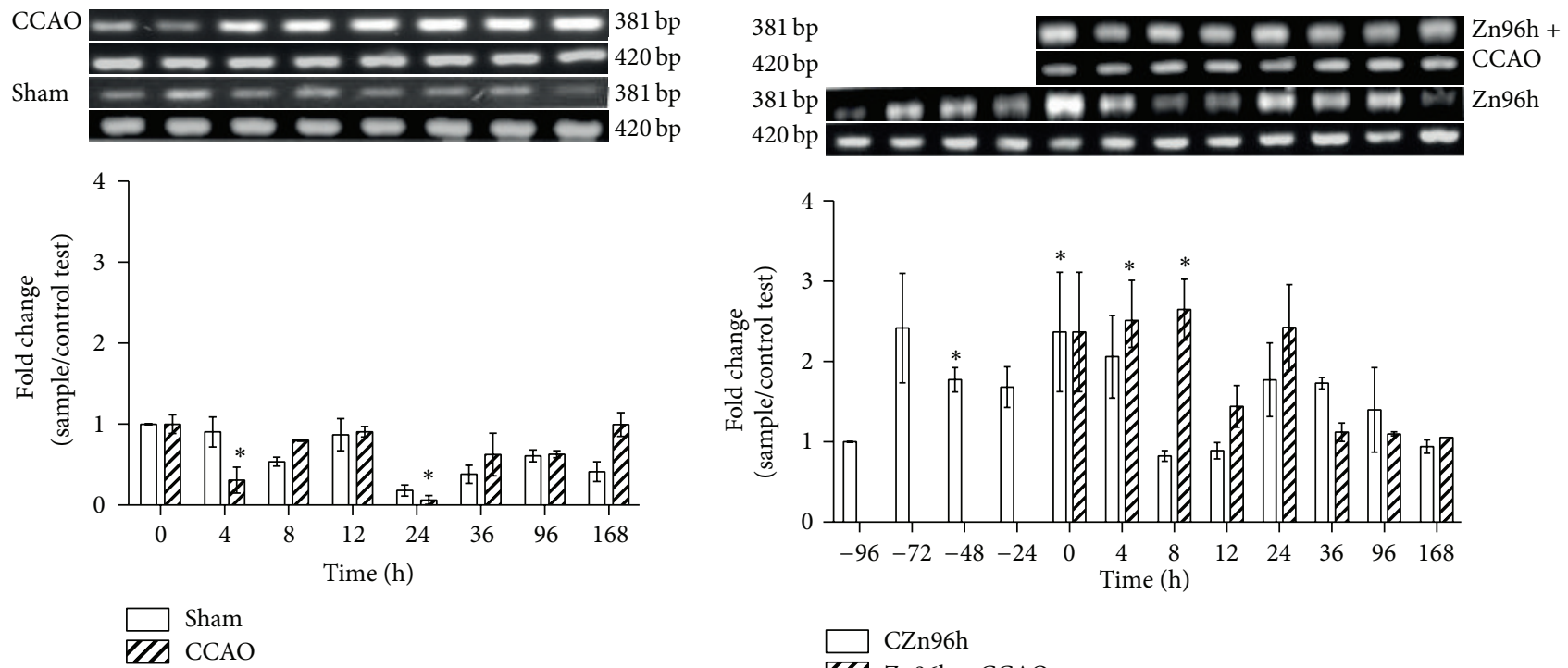

(a)
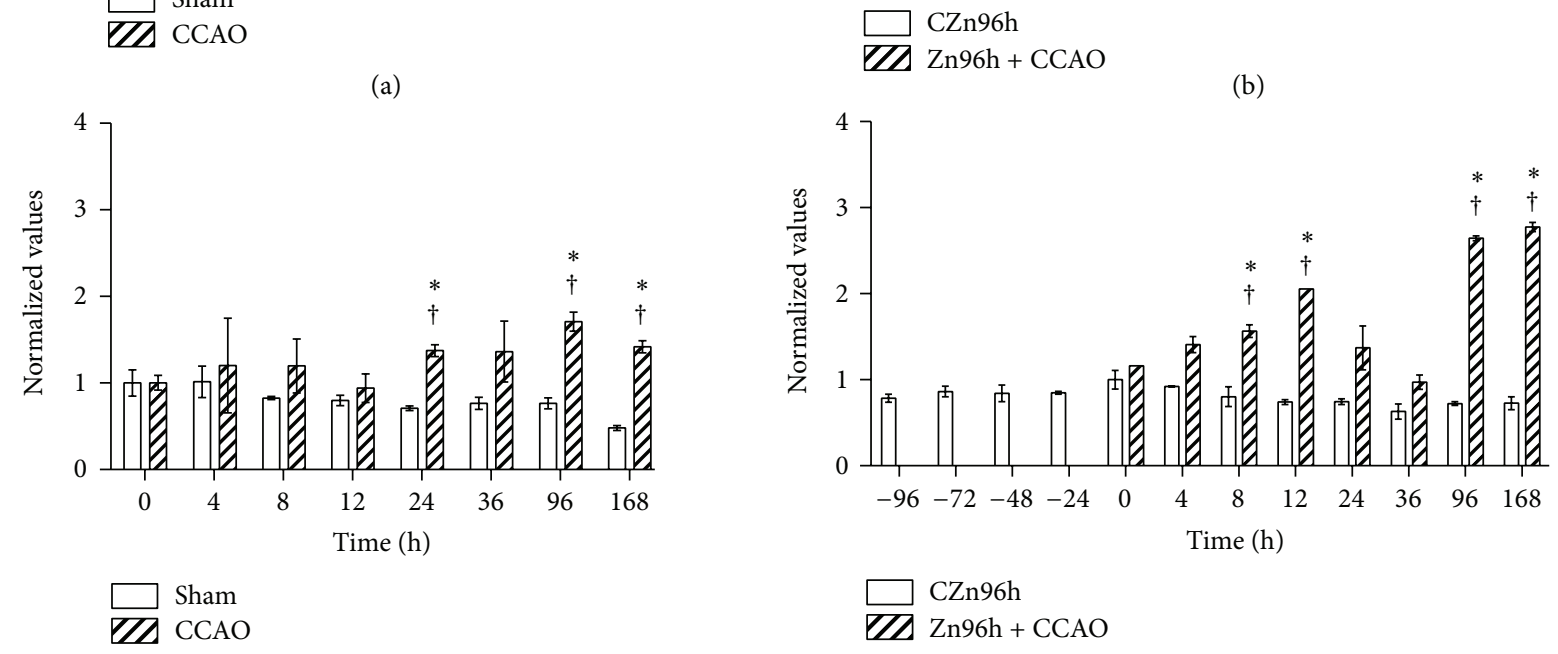

(c)

(d)

FIGURE 6: The subacute administration effect of zinc on levels of IGF-1 expression after hypoxia-ischemia in rats. RT-PCR was used to determine mRNA levels of IGF-1 (381 bp) and GA3PDH (420 bp). ((a) and (b)) Showing representative photographs of ethidium-bromidestained RT-PCR products fractionated on $2 \%$ agarose gel and the respective densitometry analysis. ((c) and (d)) Showing the IGF-1 protein levels measured using ELISA. Each value represents the mean \pm SEM of 5 independent experiments in triplicate. (1) Zn96h, rats injected with $\mathrm{ZnCl}_{2}$ (one dose every $24 \mathrm{~h}$ during 4 days). (2) $\mathrm{Zn} 96 \mathrm{~h}+\mathrm{CCAO}$, rats treated with zinc before 10 min of common carotid artery occlusion (CCAO). (3) CCAO, rats with CCAO only. (4) Sham group, rats with mock CCAO. (5) Untreated rats. *, significant when compared with the control group; ANOVA test and post hoc Dunnett's test. $\dagger$, significant when compared between groups; unpaired Student's $t$-test. $P<0.05$.

presenting cells, such as the human leukemic monoblast cell line U937 [58]. Because CCL2 plays a neuroprotective role during an ischemic preconditioning and postconditioning process [5, 40, 41], zinc finger transcription factor ZXDC might mediate CCL2-induced neuroprotection. Moreover, several references support the upregulation of CCL2 through HuR proteins, miRNAs, and inflammatory cytokines (IL-17 and TNF $\alpha$ ), which promote stability of CCL2 mRNA after their binding to ARE's regions [59-61]. These mechanisms might also mediate CCL2-induced neuroprotection administered when zinc is administered prior to the ischemic event.

Several studies support that the increase in CCL2 levels promotes the inflammatory process: such an effect has been reported to be harmful $[36-39,62,63]$. In addition, CCL2 is widely recognized to be a major component of chronic inflammation associated with a variety of diseases including obesity-associated type 2 diabetes and cardiovascular diseases $[64,65]$. Some proposed mechanisms of CCL2 inducedincrease in inflammation are the endoplasmic reticulum stress and autophagy [62].

In contrast, other studies have shown that CCL2 plays a neuroprotective role [28, 29, 35, 40, 41]. Accordingly, CCL2 upregulation after ischemic preconditioning [40] and postconditioning prevents ischemia/reperfusion-induced cerebral injury [41]. In addition, the subacute administration of zinc also caused the expression of CCR2 in granular cells of the hippocampus and pyramidal cells of the cerebral cortex in the early and late phases after CCAO, thus suggesting 


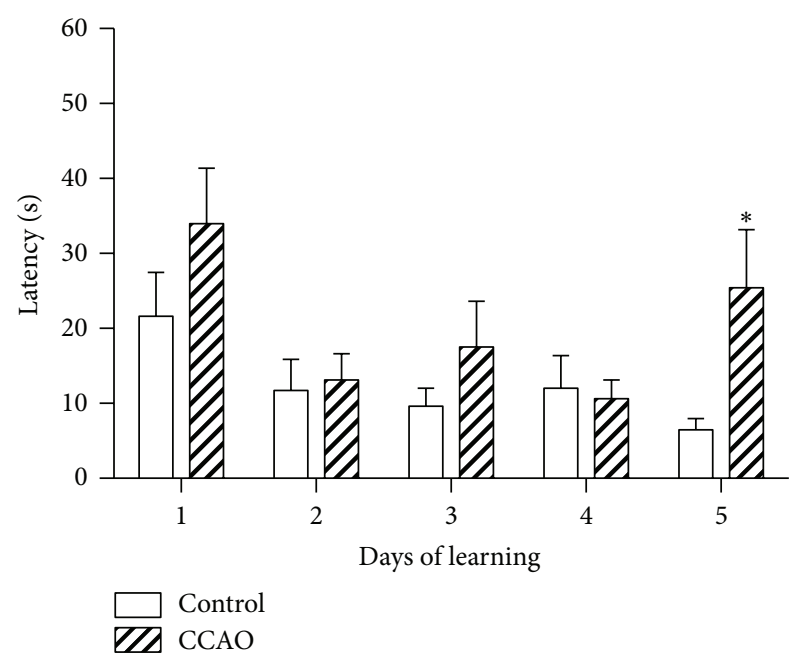

(a)

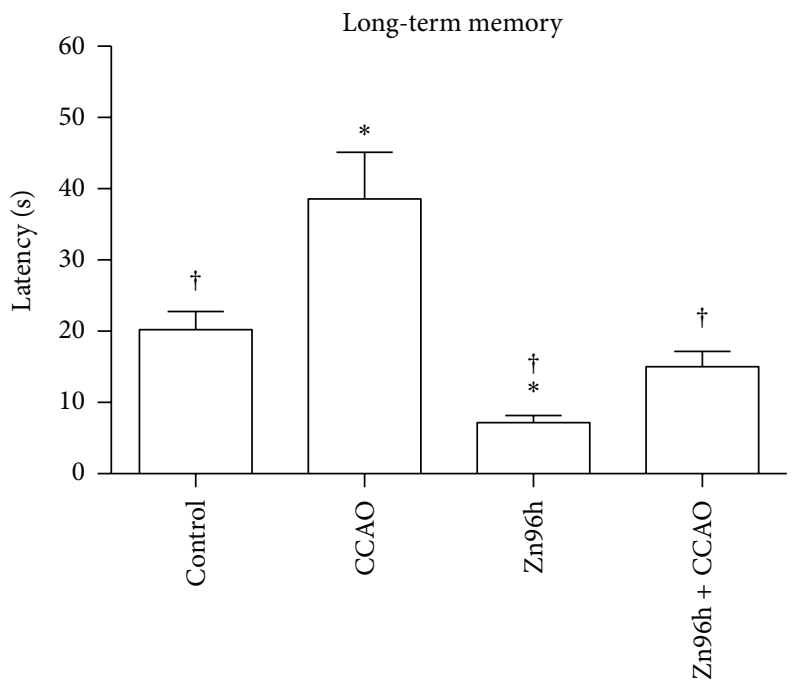

(c)

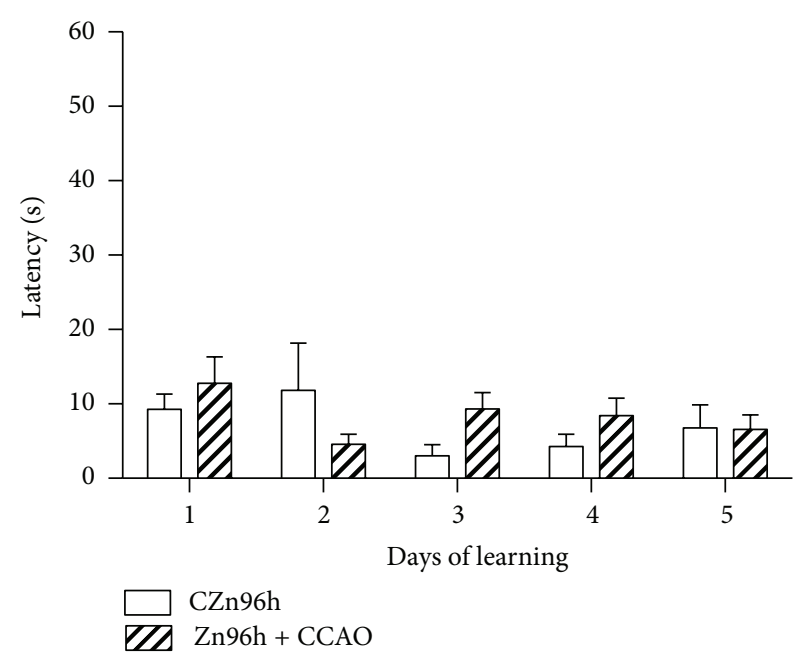

(b)

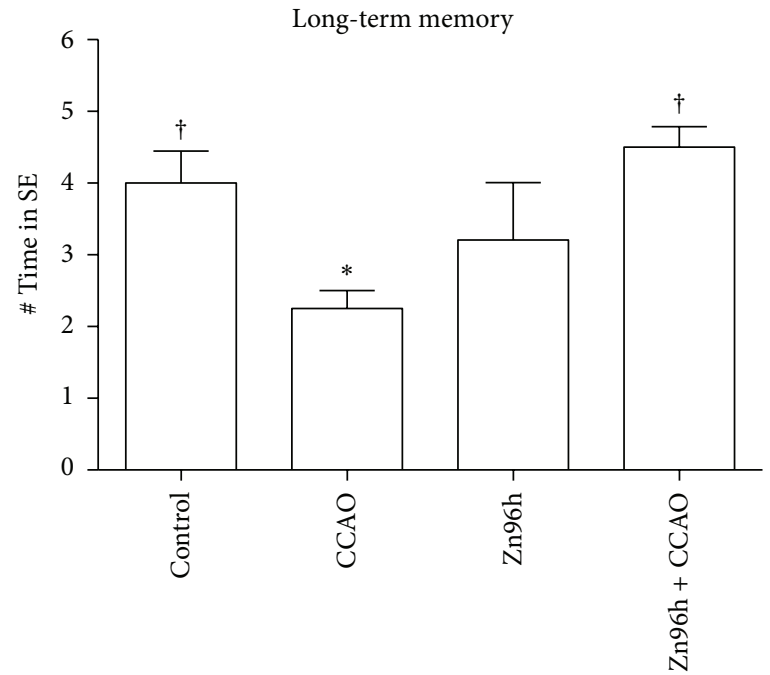

(d)

FIGURE 7: The effect of subacute administration of zinc on learning and long-term memory after hypoxia-ischemia in rats. ((a) and (b)) Graphs showing the latency to reach the escape platform in the fourth event (eastern quadrant) of a daily evaluation for five days in the Morris Water Maze ( $n=10$ rats per group). (c) Graphs showing the latency determined on day 7 after the learning training, that is, on day 12 after reperfusion ( $n=5$ rats per group). (d) Graphs showing the number of times in southeast (\# Time in SE) at which rats pass by the platform location. Evaluations were made on day 7 after the learning training. The values are the mean \pm SEM. $*$, significant when compared with the control group ANOVA test and post hoc Dunnett's test, $P<0.05$. $\dagger$, significant when compared with the CCAO group; unpaired Student's $t$-test. $P<0.05$

a reinforcement of the neuroprotective effect. In support of this suggestion, there are evidences that CCL2/CCR2 expressed in neurons during an ischemic preconditioning and postconditioning process attenuates the reperfusioninduced injury and reduces the release of systemic proinflammatory cytokines $[5,40,41]$. Moreover, CCL2/CCR2 has been reported to promote the recruitment of neural stem cells $[31,66]$. The overexpression of CCL2 together with other chemokines such as CCL3 and CXCL1 can redirect the precursor cell migration into a nonneurogenic region $[67,68]$. Thus, zinc through CCL2 and other chemokines might contribute together with neurotrophic factors in the functional restoration in animal models of neural injury and neurodegeneration.

We found that the subacute administration of zinc also increases the expression of FGF2 in the early phase and IGF-1 in the early and late phases after hypoxia-ischemia process. The increase in these growth factors might be accounted by the increased levels of CCL2 $[29,30,69]$ or by the effect of zinc through other unknown mechanisms. For instance, zinc supplement is able to increase the protein levels of IGF-1 and IGFBP3 in plasma in children [13] and FGF2 expression by myeloid zinc finger protein-1 (MZF-1) in astrocytes [70]. In addition, the presence of zinc potentiates the stimulation 
by FGF2 and FGF1 of the proliferation in cultured vascular smooth muscle cells [71].

An increasing number of studies sustain that FGF2 and IGF-1 participate in neurogenesis, neurodifferentiation, and neuron survival [30]. On this basis, we propose that the presence of FGF2 and IGF-1 in the early phase might activate the proliferation of progenitor cells and that the IGF-1 in the late phase and in the absence of FGF2 might promote the differentiation of neural precursor neurons [31].

FGF2 and IGF-1 also have an anti-inflammatory effect, by reducing the blood-brain barrier permeability at $4 \mathrm{~h}$ after stroke, suppressing the serum levels of cytokines including IL-6, IL-10, and TNF- $\alpha[72,73]$, and stimulating DNA repair, metabolic homeostasis, cytoskeletal stability, and cholesterol biosynthesis [74]. In addition, IGF-1 is known to decrease the response of microglia to ischemic stroke and lipopolysaccharides [46]. Moreover, any form of administration of IGF-1 has shown a neuroprotective effect for the treatment of acute ischemic stroke [48]. FGF2 also exhibits an antioxidant effect on the redox system and reduces the oxidative stress induced by bisphosphonate [74]. Therefore, we propose that the overexpression of FGF2 and IGF-1 induced by the subacute administration of zinc might play an antioxidant, antiinflammatory, and neurogenic role after a hypoxia-ischemia process.

Although there are various methods to measure the functionality of hippocampus, the Morris Water Maze has the advantage that it strongly correlates the measurements of spatial reference memory with the hippocampal synaptic activity and NMDA receptor function $[75,76]$. Furthermore, the task in the Morris Water Maze requires only the stimulus of escape from water. This represents an additional advantage on radial arm maze or T-maze that requires deprivation of food or water [77]. It has been reported that zinc supplementation is an effective treatment option for improving cognitive deficits $[78,79]$, but not for improving motor activity [79] in rats evaluated using the Morris Water Maze. Using this apparatus, a recent report shows that nanoZnO treatment improves the spatial memory and the synaptic plasticity, which was assessed by measuring the long-term potentiation (LTP) in the DG [80]. Our results using this behavioral test showed that the subacute zinc administration improves the long-term memory in control rats and prevents the CCAO-induced loss of spatial reference memory. An increased zinc store in synaptic vesicles of hippocampal mossy fibers might account for the beneficial effect of zinc administration on spatial reference memory because it is widely known that the corelease of zinc and glutamate from the mossy fibers favors the learning and memory [81]. In addition, an increase in FGF2 and IGF-1 expression reported here might contribute to synaptic plasticity, which would consolidate the learning and memory after CCAO [82, 83]. Other beneficial effects of FGF2 and IGF-1 involved in the subacute administration of zinc might be the stimulation of neuron survival and neurogenesis in the subventricular zone and the subgranular zone of dentate gyrus, since these events are triggered in adult rats following cerebral ischemia $[47,50]$.

\section{Conclusion}

The main outcome of this work is that the subacute administration of zinc increases the expression of CCL2, CCR2, and growth factors (FGF2 and IGF-1) as well as preventing the loss of memory in the rats after transient hypoxia-ischemia. This latter result suggests that the prophylactic administration of zinc exerts a neuroprotective effect in the cerebral hypoxiaischemia model, possibly inducing neuronal plasticity.

\section{Conflict of Interests}

The authors declare that they have no conflict of interests.

\section{Acknowledgments}

Victor Manuel Blanco-Alvarez and Constantino TomásSanchez are recipients of scholarships from CONACYT. This work was supported by VIEP (Grant NAT/2014). Thanks are due to Mira Thakur for editing the English-language text.

\section{References}

[1] V. M. Blanco-Alvarez, P. Lopez-Moreno, G. Soto-Rodriguez et al., "Subacute zinc administration and L-name caused an increase of NO, Zinc, lipoperoxidation, and caspase-3 during a cerebral hypoxia-ischemia process in the rat," Oxidative Medicine and Cellular Longevity, vol. 2013, Article ID 240560, 10 pages, 2013.

[2] Y. Kitamura, Y. Iida, J. Abe et al., "Protective effect of zinc against ischemic neuronal injury in a middle cerebral artery occlusion model," Journal of Pharmacological Sciences, vol. 100, no. 2, pp. 142-148, 2006.

[3] K. Matsushita, K. Kitagawa, T. Matsuyama et al., "Effect of systemic zinc administration on delayed neuronal death in the gerbil hippocampus," Brain Research, vol. 743, no. 1-2, pp. 362365, 1996.

[4] T. Miyawaki, H. Yokota, K. Oguro, K. Kato, and K. Shimazaki, "Ischemic preconditioning decreases intracellular zinc accumulation induced by oxygen-glucose deprivation in gerbil hippocampal CA1 neurons," Neuroscience Letters, vol. 362, no. 3, pp. 216-219, 2004.

[5] T. Xu, Z. Gong, W.-Z. Zhu et al., "Remote ischemic preconditioning protects neurocognitive function of rats following cerebral hypoperfusion," Medical Science Monitor, vol. 17, no. 11, pp. 299-304, 2011.

[6] J.-Y. Lee, Y.-J. Kim, T.-Y. Kim, J.-Y. Koh, and Y.-H. Kim, “Essential role for zinc-triggered $\mathrm{p} 75^{\mathrm{NTR}}$ activation in preconditioning neuroprotection," Journal of Neuroscience, vol. 28, no. 43, pp. 10919-10927, 2008.

[7] C. J. Frederickson, J.-Y. Koh, and A. I. Bush, "The neurobiology of zinc in health and disease," Nature Reviews Neuroscience, vol. 6, no. 6, pp. 449-462, 2005.

[8] C. J. Frederickson, L. J. Giblin, A. Krezel et al., "Concentrations of extracellular free zinc (pZn)e in the central nervous system during simple anesthetization, ischemia and reperfusion," Experimental Neurology, vol. 198, no. 2, pp. 285-293, 2006.

[9] M. A. Aras, H. Hara, K. A. Hartnett, K. Kandler, and E. Aizenman, "Protein kinase $\mathrm{C}$ regulation of neuronal zinc signaling mediates survival during preconditioning," Journal of Neurochemistry, vol. 110, no. 1, pp. 106-117, 2009. 
[10] G.-Q. Huang, J.-N. Wang, J.-M. Tang et al., “The combined transduction of copper, zinc-superoxide dismutase and catalase mediated by cell-penetrating peptide, PEP-1, to protect myocardium from ischemia-reperfusion injury," Journal of Translational Medicine, vol. 9, article 73, 2011.

[11] Y.-E. Zhang, S.-Z. Fu, X.-Q. Li et al., "PEP-1-SOD1 protects brain from ischemic insult following asphyxial cardiac arrest in rats," Resuscitation, vol. 82, no. 8, pp. 1081-1086, 2011.

[12] P. H. Chan, "Antioxidant-dependent amelioration of brain injury: role of CuZn-superoxide dismutase," Journal of Neurotrauma, vol. 9, supplement 2, pp. S417-S423, 1992.

[13] C. X. Alves, S. H. L. Vale, M. M. G. Dantas et al., "Positive effects of zinc supplementation on growth, GH, IGF1, and IGFBP3 in eutrophic children," Journal of Pediatric Endocrinology and Metabolism, vol. 25, no. 9-10, pp. 881-887, 2012.

[14] M. A. Aras and E. Aizenman, "Redox regulation of intracellular zinc: molecular signaling in the life and death of neurons," Antioxidants and Redox Signaling, vol. 15, no. 8, pp. 2249-2263, 2011.

[15] G. K. Helal, "Systemic administration of $\mathrm{Zn}^{2+}$ during the reperfusion phase of transient cerebral ischaemia protects rat hippocampus against iron-catalysed postischaemic injury," Clinical and Experimental Pharmacology and Physiology, vol. 35, no. 7, pp. 775-781, 2008.

[16] B. Bao, A. S. Prasad, F. W. J. Beck et al., "Zinc decreases Creactive protein, lipid peroxidation, and inflammatory cytokines in elderly subjects: a potential implication of zinc as an atheroprotective agent," The American Journal of Clinical Nutrition, vol. 91, no. 6, pp. 1634-1641, 2010.

[17] Y. Xie, S. Chen, Y. Wu, and T. H. Murphy, "Prolonged deficits in parvalbumin neuron stimulation-evoked network activity despite recovery of dendritic structure and excitability in the somatosensory cortex following global ischemia in mice," The Journal of Neuroscience, vol. 34, no. 45, pp. 14890-14900, 2014.

[18] A. M. Vergnano, N. Rebola, L. P. Savtchenko et al., "Zinc dynamics and action at excitatory synapses," Neuron, vol. 82, no. 5, pp. 1101-1114, 2014.

[19] A. Prakash, K. Bharti, and A. B. Majeed, "Zinc: indications in brain disorders," Fundamental \& Clinical Pharmacology, vol. 29, no. 2, pp. 131-149, 2015.

[20] T. Nishi, C. M. Maier, T. Hayashi, A. Saito, and P. H. Chan, "Superoxide dismutase 1 overexpression reduces MCP-1 and MIP- $1 \alpha$ expression after transient focal cerebral ischemia," Journal of Cerebral Blood Flow and Metabolism, vol. 25, no. 10, pp. 1312-1324, 2005.

[21] J. Losy and J. Zaremba, "Monocyte chemoattractant protein-1 is increased in the cerebrospinal fluid of patients with ischemic stroke," Stroke, vol. 32, no. 11, pp. 2695-2696, 2001.

[22] J. Zaremba, J. Ilkowski, and J. Losy, "Serial measurements of levels of the chemokines CCL2, CCL3 and CCL5 in serum of patients with acute ischaemic stroke," Folia Neuropathologica, vol. 44, no. 4, pp. 282-289, 2006.

[23] J. Losy, J. Zaremba, and P. Skrobański, "CXCL1 (GRO-alpha) chemokine in acute ischaemic stroke patients," Folia Neuropathologica, vol. 43, no. 2, pp. 97-102, 2005.

[24] J. Mojsilovic-Petrovic, D. Callaghan, H. Cui, C. Dean, D. B. Stanimirovic, and W. Zhang, "Hypoxia-inducible factor-1 (HIF1) is involved in the regulation of hypoxia-stimulated expression of monocyte chemoattractant protein-1 (MCP-1/CCL2) and MCP-5 (Ccl12) in astrocytes," Journal of Neuroinflammation, vol. 4 , article 12, 2007.
[25] X. Che, W. Ye, L. Panga, D.-C. Wu, and G.-Y. Yang, "Monocyte chemoattractant protein-1 expressed in neurons and astrocytes during focal ischemia in mice," Brain Research, vol. 902, no. 2, pp. 171-177, 2001.

[26] S. Liu, L. Zhang, Q. Wu, and T. Wang, "Chemokine $\mathrm{CCL}_{2}$ induces apoptosis in cortex following traumatic brain injury," Journal of Molecular Neuroscience, vol. 51, no. 3, pp. 1021-1029, 2013.

[27] Y. Chen, J. M. Hallenbeck, C. Ruetzler et al., "Overexpression of monocyte chemoattractant protein 1 in the brain exacerbates ischemic brain injury and is associated with recruitment of inflammatory cells," Journal of Cerebral Blood Flow and Metabolism, vol. 23, no. 6, pp. 748-755, 2003.

[28] A. Stålman, D. Bring, and P. W. Ackermann, "Chemokine expression of CCL2, CCL3, CCL5 and CXCL10 during early inflammatory tendon healing precedes nerve regeneration: an immunohistochemical study in the rat," Knee Surgery, Sports Traumatology, Arthroscopy, 2014.

[29] A. N. Kalehua, J. E. Nagel, L. M. Whelchel et al., "Monocyte chemoattractant protein-1 and macrophage inflammatory protein-2 are involved in both excitotoxin-induced neurodegeneration and regeneration," Experimental Cell Research, vol. 297, no. 1, pp. 197-211, 2004.

[30] H. S. G. Kalluri, R. Vemuganti, and R. J. Dempsey, "Mechanism of insulin-like growth factor I-mediated proliferation of adult neural progenitor cells: role of Akt," European Journal of Neuroscience, vol. 25, no. 4, pp. 1041-1048, 2007.

[31] H. S. G. Kalluri and R. J. Dempsey, "Growth factors, stem cells, and stroke," Neurosurgical Focus, vol. 24, no. 3-4, p. E13, 2008.

[32] L. Ruan, B. Wang, Q. ZhuGe, and K. Jin, "Coupling of neurogenesis and angiogenesis after ischemic stroke," Brain Research, 2015.

[33] S. Mélik-Parsadaniantz, "CCL2 chemokine and transmission of nociceptive information," Biologie Aujourd'hui, vol. 204, no. 4, pp. 301-309, 2010.

[34] J. G. Bray, K. C. Reyes, A. J. Roberts, R. M. Ransohoff, and D. L. Gruol, "Synaptic plasticity in the hippocampus shows resistance to acute ethanol exposure in transgenic mice with astrocytetargeted enhanced CCL2 expression," Neuropharmacology, vol. 67, pp. 115-125, 2013.

[35] Y. Sakurai-Yamashita, K. Shigematsu, K. Yamashita, and M. Niwa, "Expression of MCP-1 in the hippocampus of SHRSP with ischemia-related delayed neuronal death," Cellular and Molecular Neurobiology, vol. 26, no. 4-6, pp. 823-831, 2006.

[36] N. Tei, J. Tanaka, K. Sugimoto et al., "Expression of MCP-1 and fractalkine on endothelial cells and astrocytes may contribute to the invasion and migration of brain macrophages in ischemic rat brain lesions," Journal of Neuroscience Research, vol. 91, no. 5, pp. 681-693, 2013.

[37] S. Yamagami, M. Tamura, M. Hayashi et al., "Differential production of MCP-1 and cytokine-induced neutrophil chemoattractant in the ischemic brain after transient focal ischemia in rats," Journal of Leukocyte Biology, vol. 65, no. 6, pp. 744-749, 1999.

[38] O. B. Dimitrijevic, S. M. Stamatovic, R. F. Keep, and A. V. Andjelkovic, "Effects of the chemokine CCL2 on blood-brain barrier permeability during ischemia-reperfusion injury," Journal of Cerebral Blood Flow \& Metabolism, vol. 26, no. 6, pp. 797810, 2006. 
[39] O. B. Dimitrijevic, S. M. Stamatovic, R. F. Keep, and A. V. Andjelkovic, "Absence of the chemokine receptor CCR2 protects against cerebral ischemia/reperfusion injury in mice," Stroke, vol. 38, no. 4, pp. 1345-1353, 2007.

[40] A. M. Stowe, B. K. Wacker, P. D. Cravens et al., "CCL2 upregulation triggers hypoxic preconditioning-induced protection from stroke," Journal of Neuroinflammation, vol. 9, article 33, 2012.

[41] A. K. Rehni and T. G. Singh, "Involvement of CCR-2 chemokine receptor activation in ischemic preconditioning and postconditioning of brain in mice," Cytokine, vol. 60, no. 1, pp. 83-89, 2012.

[42] O. Gonzalez-Perez, F. Jauregui-Huerta, and A. Y. GalvezContreras, "Immune system modulates the function of adult neural stem cells," Current Immunology Reviews, vol. 6, no. 3, pp. 167-173, 2010.

[43] M. Naylor, K. K. Bowen, K. A. Sailor, R. J. Dempsey, and R. Vemuganti, "Preconditioning-induced ischemic tolerance stimulates growth factor expression and neurogenesis in adult rat hippocampus," Neurochemistry International, vol. 47, no. 8, pp. 565-572, 2005.

[44] J. L. Herrmann, Y. Wang, A. M. Abarbanell, B. R. Weil, J. Tan, and D. R. Meldrum, "Preconditioning mesenchymal stem cells with transforming growth factor-alpha improves mesenchymal stem cell-mediated cardioprotection," Shock, vol. 33, no. 1, pp. 24-30, 2010.

[45] H.-C. Chang, Y.-R. Yang, P. S. Wang, C.-H. Kuo, and R.-Y. Wang, "The neuroprotective effects of intramuscular insulinlike growth factor-I treatment in brain ischemic rats," PLoS ONE, vol. 8, no. 5, Article ID e64015, 2013.

[46] D. De Geyter, W. Stoop, S. Sarre, J. De Keyser, and R. Kooijman, "Neuroprotective efficacy of subcutaneous insulin-like growth factor-I administration in normotensive and hypertensive rats with an ischemic stroke," Neuroscience, vol. 250, pp. 253-262, 2013.

[47] S. Jin-qiao, S. Bin, Z. Wen-hao, and Y. Yi, "Basic fibroblast growth factor stimulates the proliferation and differentiation of neural stem cells in neonatal rats after ischemic brain injury," Brain and Development, vol. 31, no. 5, pp. 331-340, 2009.

[48] R. Kooijman, S. Sarre, Y. Michotte, and J. D. Keyser, "Insulinlike growth factor I: a potential neuroprotective compound for the treatment of acute ischemic stroke?" Stroke, vol. 40, no. 4, pp. e83-e88, 2009.

[49] Z. Wang, H. Zhang, X. Xu et al., "BFGF inhibits ER stress induced by ischemic oxidative injury via activation of the PI3K/ Akt and ERK1/2 pathways," Toxicology Letters, vol. 212, no. 2, pp. 137-146, 2012.

[50] Z.-L. Wang, S.-M. Cheng, M.-M. Ma et al., "Intranasally delivered bFGF enhances neurogenesis in adult rats following cerebral ischemia," Neuroscience Letters, vol. 446, no. 1, pp. 30-35, 2008.

[51] S. Elkabes and A. B. Nicot, "Sex steroids and neuroprotection in spinal cord injury: a review of preclinical investigations.," Experimental neurology, vol. 259, pp. 28-37, 2014.

[52] B. Gürer, H. Kertmen, E. Kasim et al., "Neuroprotective effects of testosterone on ischemia/reperfusion injury of the rabbit spinal cord," Injury, vol. 46, no. 2, pp. 240-248, 2015.

[53] M. Beltramini, P. Zambenedetti, W. Wittkowski, and P. Zatta, "Effects of steroid hormones on the Zn, Cu and MTI/II levels in the mouse brain," Brain Research, vol. 1013, no. 1, pp. 134-141, 2004.

[54] B. Alicia Leon-Chavez, P. Aguilar-Alonso, J. A. GonzalezBarrios et al., "Increased nitric oxide levels and nitric oxide synthase isoform expression in the cerebellum of the taiep rat during its severe demyelination stage," Brain Research, vol. 1121, no. 1, pp. 221-230, 2006.

[55] J. J. Sedmak and S. E. Grossberg, "A rapid, sensitive, and versatile assay for protein using Coomassie brilliant blue G250," Analytical Biochemistry, vol. 79, no. 1-2, pp. 544-552, 1977.

[56] J. A. Gonzalez-Barrios, B. Escalante, J. Valdés, B. A. LeónChávez, and D. Martinez-Fong, "Nitric oxide and nitric oxide synthases in the fetal cerebral cortex of rats following transient uteroplacental ischemia," Brain Research, vol. 945, no. 1, pp. 114$122,2002$.

[57] R. Morris, "Developments of a water-maze procedure for studying spatial learning in the rat," Journal of Neuroscience Methods, vol. 11, no. 1, pp. 47-60, 1984.

[58] J. E. Ramsey and J. D. Fontes, "The zinc finger transcription factor ZXDC activates CCL2 gene expression by opposing BCL6-mediated repression," Molecular Immunology, vol. 56, no. 4, pp. 768-780, 2013.

[59] R. P. Panganiban, B. M. Vonakis, F. T. Ishmael, and C. Stellato, "Coordinated post-transcriptional regulation of the chemokine system: messages from $\mathrm{CCL}_{2}$," Journal of Interferon and Cytokine Research, vol. 34, no. 4, pp. 255-266, 2014.

[60] J. Fan, N. M. Heller, M. Gorospe, U. Atasoy, and C. Stellato, "The role of post-transcriptional regulation in chemokine gene expression in inflammation and allergy," European Respiratory Journal, vol. 26, no. 5, pp. 933-947, 2005.

[61] T. Hamilton, M. Novotny, P. J. Pavicic et al., "Diversity in posttranscriptional control of neutrophil chemoattractant cytokine gene expression," Cytokine, vol. 52, no. 1-2, pp. 116-122, 2010.

[62] P. E. Kolattukudy and J. Niu, "Inflammation, endoplasmic reticulum stress, autophagy, and the monocyte chemoattractant protein-1/CCR2 pathway," Circulation Research, vol. 110, no. 1, pp. 174-189, 2012.

[63] M. Schilling, J.-K. Strecker, W.-R. Schäbitz, E. B. Ringelstein, and R. Kiefer, "Effects of monocyte chemoattractant protein 1 on blood-borne cell recruitment after transient focal cerebral ischemia in mice," Neuroscience, vol. 161, no. 3, pp. 806-812, 2009.

[64] J. Niu and P. E. Kolattukudy, "Role of MCP-1 in cardiovascular disease: molecular mechanisms and clinical implications," Clinical Science, vol. 117, no. 3, pp. 95-109, 2009.

[65] H.-M. Woo, J.-H. Kang, T. Kawada, H. Yoo, M.-K. Sung, and R. Yu, "Active spice-derived components can inhibit inflammatory responses of adipose tissue in obesity by suppressing inflammatory actions of macrophages and release of monocyte chemoattractant protein-1 from adipocytes," Life Sciences, vol. 80, no. 10, pp. 926-931, 2007.

[66] R. H. Andres, R. Choi, A. V. Pendharkar et al., "The CCR2/ CCL2 interaction mediates the transendothelial recruitment of intravascularly delivered neural stem cells to the ischemic brain," Stroke, vol. 42, no. 10, pp. 2923-2931, 2011.

[67] R. J. Gordon, A. L. McGregor, and B. Connor, "Chemokines direct neural progenitor cell migration following striatal cell loss," Molecular and Cellular Neuroscience, vol. 41, no. 2, pp. 219232, 2009.

[68] S. K. Tang, R. A. Knobloch, C. Maucksch, and B. Connor, "Redirection of doublecortin-positive cell migration by overexpression of the chemokines MCP-1, MIP-lalpha and GROalpha in the adult rat brain," Neuroscience, vol. 260, pp. 240-248, 2014.

[69] A. E. Hinojosa, B. Garcia-Bueno, J. C. Leza, and J. L. M. Madrigal, "CCL2/MCP-1 modulation of microglial activation 
and proliferation," Journal of Neuroinflammation, vol. 8, article 77, 2011.

[70] X. Luo, X. Zhang, W. Shao, Y. Yin, and J. Zhou, "Crucial roles of MZF-1 in the transcriptional regulation of apomorphineinduced modulation of FGF-2 expression in astrocytic cultures," Journal of Neurochemistry, vol. 108, no. 4, pp. 952-961, 2009.

[71] Y. Fujiwara and T. Kaji, "Zinc potentiates the stimulation by basic and acidic fibroblast growth factors on the proliferation of cultured vascular smooth muscle cells," Research Communications in Molecular Pathology and Pharmacology, vol. 97, no. 1, pp. 95-106, 1997.

[72] S. Bake, A. Selvamani, J. Cherry, and F. Sohrabji, "Blood brain barrier and neuroinflammation are critical targets of IGF-1mediated neuroprotection in stroke for middle-aged female rats," PLoS ONE, vol. 9, no. 3, Article ID e91427, 2014.

[73] G. Koçer, M. Nazıroğlu, Ö. Çelik et al., "Basic fibroblast growth factor attenuates bisphosphonate-induced oxidative injury but decreases zinc and copper levels in oral epithelium of rat," Biological Trace Element Research, vol. 153, no. 1-3, pp. 251-256, 2013.

[74] E. Yoshida, T. G. Atkinson, and B. Chakravarthy, "Neuroprotective gene expression profiles in ischemic cortical cultures preconditioned with IGF-1 or bFGF," Molecular Brain Research, vol. 131, no. 1-2, pp. 33-50, 2004.

[75] M. M. Adams, T. D. Smith, D. Moga et al., "Hippocampal dependent learning ability correlates with N-methyl-Daspartate (NMDA) receptor levels in CA3 neurons of young and aged rats," Journal of Comparative Neurology, vol. 432, no. 2, pp. 230-243, 2001.

[76] V. Ramíarez-Amaya, I. Balderas, J. Sandoval, M. L. Escobar, and F. Bermúdez-Rattoni, "Spatial long-term memory is related to mossy fiber synaptogenesis," Journal of Neuroscience, vol. 21, no. 18, pp. 7340-7348, 2001.

[77] K. M. Frick, M. G. Baxter, A. L. Markowska, D. S. Olton, and D. L. Price, "Age-related spatial reference and working memory deficits assessed in the water maze," Neurobiology of Aging, vol. 16, no. 2, pp. 149-160, 1995.

[78] E. C. Cope, D. R. Morris, A. G. Scrimgeour, and C. W. Levenson, "Use of zinc as a treatment for traumatic brain injury in the rat: effects on cognitive and behavioral outcomes," Neurorehabilitation and Neural Repair, vol. 26, no. 7, pp. 907-913, 2012.

[79] S. T. Boroujeni, N. Naghdi, M. Shahbazi et al., "The effect of severe zinc deficiency and zinc supplement on spatial learning and memory," Biological Trace Element Research, vol. 130, no. 1, pp. 48-61, 2009.

[80] Y. Xie, Y. Wang, T. Zhang, G. Ren, and Z. Yang, "Effects of nanoparticle zinc oxide on spatial cognition and synaptic plasticity in mice with depressive-like behaviors," Journal of Biomedical Science, vol. 19, no. 1, pp. 1-11, 2012.

[81] J. Ceccom, E. Bouhsira, H. Halley, S. Daumas, and J. M. Lassalle, "Differential needs of zinc in the CA3 area of dorsal hippocampus for the consolidation of contextual fear and spatial memories," Learning \& Memory, vol. 20, no. 7, pp. 348351, 2013.

[82] S. Zechel, S. Werner, K. Unsicker, and O. von Bohlen und Halbach, "Expression and functions of fibroblast growth factor 2 (FGF-2) in hippocampal formation," Neuroscientist, vol. 16, no. 4, pp. 357-373, 2010.

[83] Q. Ding, S. Vaynman, M. Akhavan, Z. Ying, and F. GomezPinilla, "Insulin-like growth factor I interfaces with brainderived neurotrophic factor-mediated synaptic plasticity to modulate aspects of exercise-induced cognitive function," $\mathrm{Neu}$ roscience, vol. 140, no. 3, pp. 823-833, 2006. 

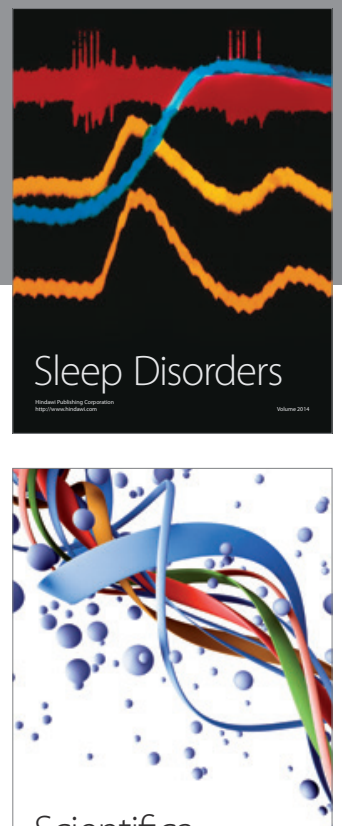

Scientifica
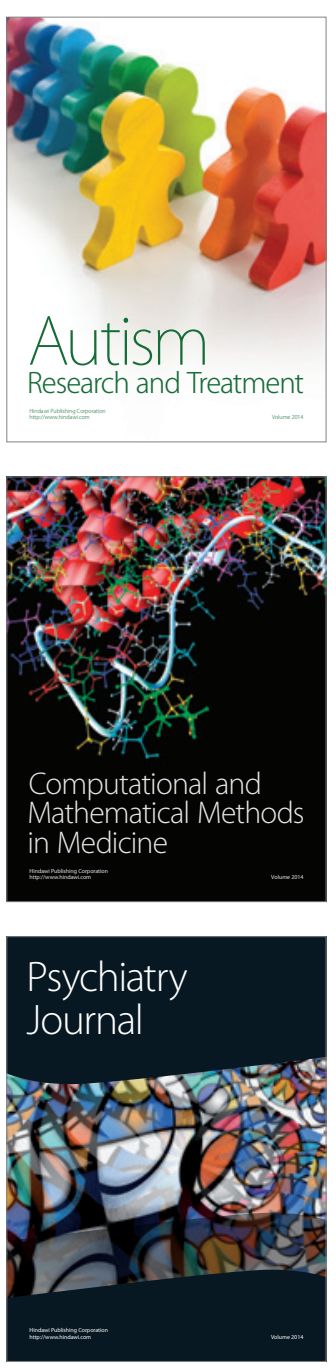
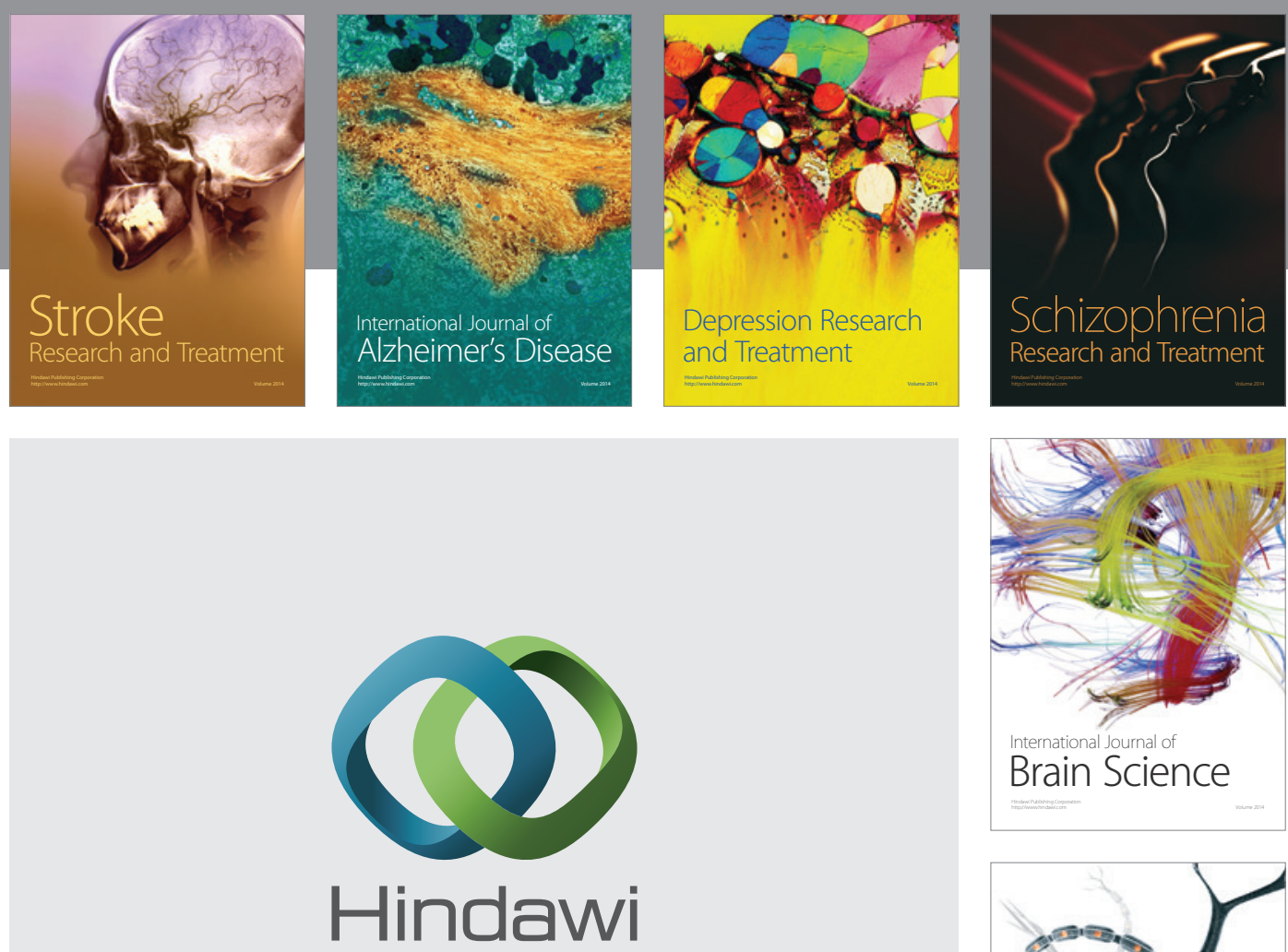

Submit your manuscripts at

http://www.hindawi.com
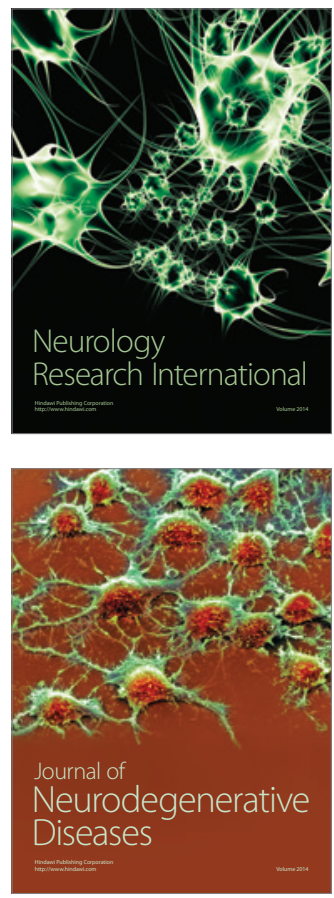

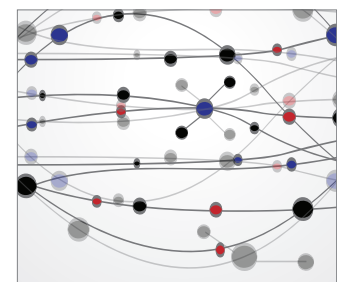

The Scientific World Journal
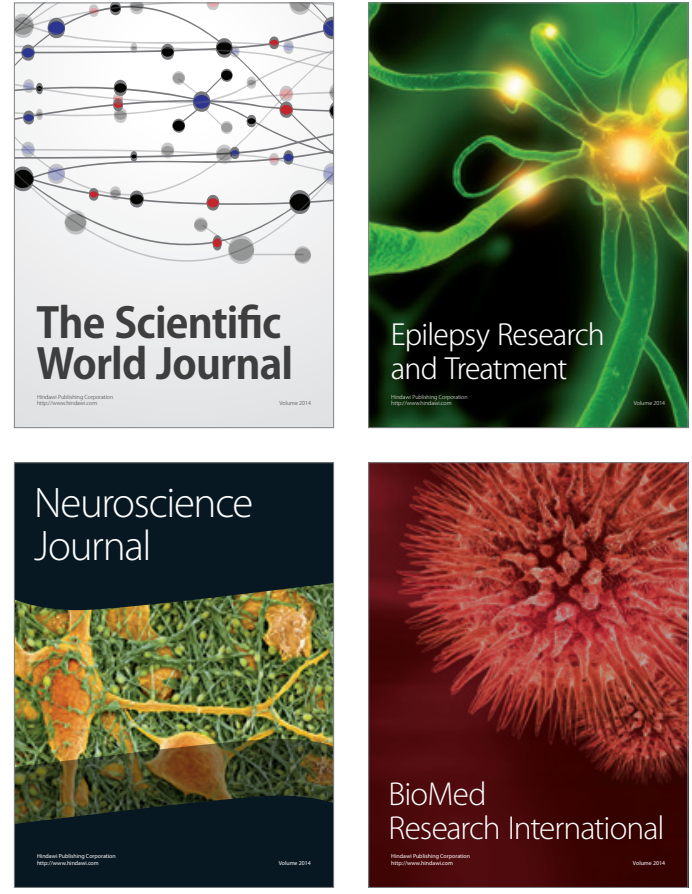

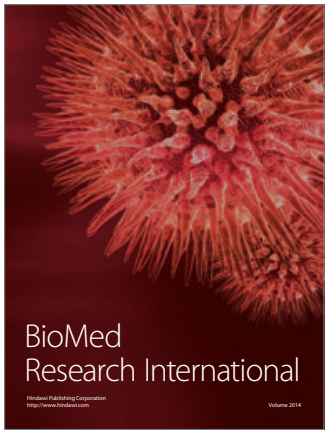

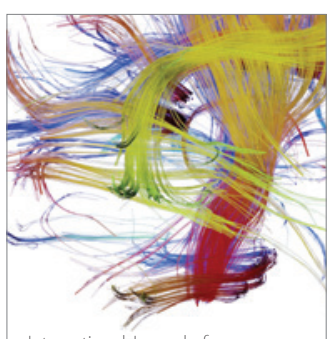

Brain Science

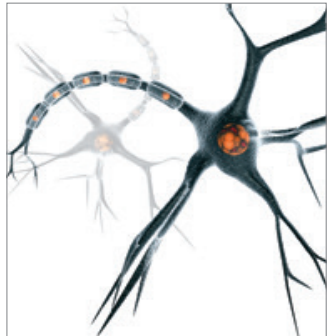

Neural Plasticity
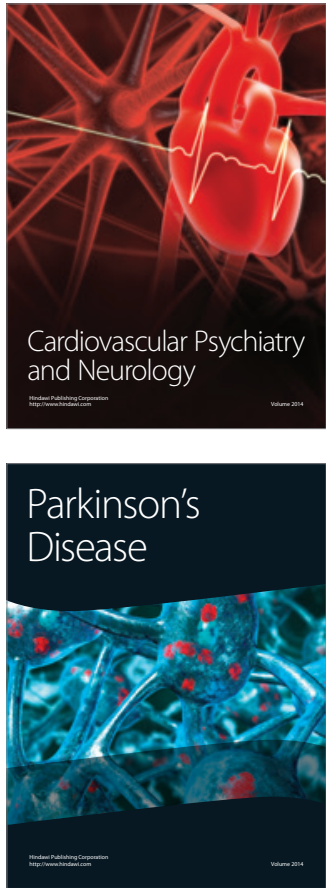